Manuscript received February 2, 2018; accepted for publication April 13, 2018; published online September 7, 2018. Issue published March 1, 2020.

1 Laboratory of Materials Science and Engineering, University of Cantabria, E.T.S. de Ingenieros de Caminos, Canales y Puertos, Av/Los Castros 44, Santander 39005, Spain

2 Department of New Sciences and Technologies, Fracture Research Laboratory, University of Tehran, N. Karegar St., P.O. Box 143951561, Tehran, Iran

${ }^{3}$ Laboratory of Materials Science and Engineering, University of Cantabria, E.T.S. de Ingenieros de Caminos, Canales y Puertos, Av/Los Castros 44, Santander 39005, Spain (Corresponding author), e-mail: fig67@alumnos. unican.es, (1) https://orcid.org/ 0000-0002-5098-3012

${ }^{4}$ Department of Mechanical Engineering, School of Mechanical Engineering, Iran University of Science and Technology, P.O. Box 16846-13114, Narmak, Tehran, Iran
S. Cicero, ${ }^{1}$ A. R. Torabi, $^{2}$ F. T. Ibáñez-Gutiérrez, ${ }^{3}$ and P. Azizi ${ }^{4}$

\section{Fracture Load Predictions in Short Glass Fiber Reinforced Polyamide 6 U-Notched Specimens Combining the Equivalent Material Concept and the Theory of Critical Distances}

\section{Reference}

S. Cicero, A. R. Torabi, F. T. Ibáñez-Gutiérrez, and P. Azizi, "Fracture Load Predictions in Short Glass Fiber Reinforced Polyamide 6 U-Notched Specimens Combining the Equivalent Material Concept and the Theory of Critical Distances," Journal of Testing and Evaluation 48, no. 2 (March/April 2020): 1226-1251. https://doi.org/10.1520/JTE20180086

\section{ABSTRACT}

This article provides the prediction of fracture loads in single edge notched bending (SENB) specimens made of short glass fiber reinforced polyamide 6 (SGFR-PA6) and containing U-notches. The predictions are obtained through the combination of the equivalent material concept and the theory of critical distances (TCD). The latter is based on the material critical distance $(L)$ and has a linearelastic nature. This implies that in those materials exhibiting non-fully linear-elastic behavior, the determination of the material critical distance requires a calibration process that may be performed by fracture testing on notched specimens or through a combination of fracture testing and finite elements simulation. This represents a significant barrier for the application of the TCD on an industrial level. The proposed methodology defines an equivalent linear-elastic material on which the TCD may be applied through its basic formulation and without any previous calibration of the corresponding critical distance. It is applied to SGFR-PA6 SENB specimens, providing accurate predictions of the experimental fracture loads.

\section{Keywords}

equivalent material concept, fracture load, notch, short glass fiber reinforced polyamide 6 , theory of critical distances 


\section{Nomenclature}

$a=$ defect size

$B=$ specimen thickness

$e_{\max }=$ engineering strain under maximum load

$E=$ elastic modulus

$K=$ strain-hardening coefficient

$K_{c}=$ fracture toughness

$K_{I}=$ stress intensity factor

$L=$ critical distance

$n=$ strain-hardening exponent

$P^{L M}{ }_{e s t}=$ estimation of critical load using the Line Method

$P^{P M}{ }_{\text {est }}=$ estimation of critical load using the Point Method

$P_{\max }=$ maximum (critical) load

$W=$ specimen width

$\varepsilon_{f}^{*}=$ strain at crack initiation for the virtual brittle material

$\varepsilon_{P}=$ true plastic strain

$\varepsilon_{u}=$ engineering plastic strain at maximum load

$\varepsilon_{u, \text { True }}=$ true plastic strain at maximum load

$\varepsilon_{y}=$ elastic strain at yield point

$\varepsilon^{Y}{ }_{P}=$ true plastic strain at yield point

$\rho=$ notch radius

$\sigma=$ true stress

$\sigma_{a v}=$ average stress along a given distance

$\sigma_{f}^{*}=$ tensile stress at crack initiation for the virtual brittle material

$\sigma_{u}=$ ultimate tensile strength

$\sigma_{y}=$ yield strength

$\sigma_{0}=$ inherent strength

$\sigma_{0.2}=0.2 \%$ proof strength

\section{Introduction}

The analysis of the fracture behavior of materials and structural components containing notches is the subject of extensive research. Notches can be understood as any kind of macroscopic stress risers in the material, although not necessarily crack-like defects. They may be responsible for structural failures caused by static fracture-plastic collapse processes, or they may be the initiators of fatigue processes that may cause a crack to initiate, propagate, and eventually lead to failure. Hence, there are numerous practical situations where the defects responsible for structural failures are not crack-like defects. In such cases, it is generally over-conservative to proceed on the assumption that the defects behave like sharp cracks, given that notched components develop a load-bearing capacity that is greater than that developed by cracked components.

This particular nature of notches makes it necessary to develop specific approaches for the fracture analysis of this type of defects. In this regard, the analysis of the fracture behavior of notches can be performed using different criteria, such as the different methodologies included within the theory of critical distances (TCD) (e.g., [1-10]), the global criterion (e.g., [11,12]), cohesive zone models (e.g., [13-17]), statistical models 
(e.g., [18,19]), mechanistic models (e.g., [20-23]), the strain energy density (SED) criterion (e.g., [24-41]), etc. The TCD methodologies have been successfully applied to different failure mechanisms (e.g., fracture, fatigue) and materials and are particularly simple to implement in structural integrity assessments [7,42-46]. The TCD is based on linearelastic assumptions, although it has been successfully applied to elastic-plastic situations either through the direct consideration of elastic-plastic stress fields [2] or through the assumption of linear-elastic behavior (stress field) and the corresponding calibration of the material critical distance (see the section titled "Theoretical Background") (e.g., [4,5]). However, when the material behavior is not fully linear-elastic, the application of the TCD requires the fracture testing of notched specimens, finite elements (FE) modeling, or both, in order to calibrate the material parameters involved. This makes it difficult to apply the TCD on an industrial level.

Hence, when analyzing the fracture behavior of an elastic-plastic material, and in order to avoid the previously referenced difficulties, Torabi $[47,48]$ proposed the use of the equivalent material concept (EMC) to define an equivalent linear-elastic material that shows the same fracture behavior. This proposal has been combined with the TCD [49-55] or the SED criterion [56-61], providing accurate analyses of the fracture behavior of different materials such as $\mathrm{Al}$ 6061-T6, Al 7075-T6, and ductile steels.

Moreover, short fiber reinforced thermoplastics are an important type of engineering plastics that are replacing metallic parts in engineering components because of their simple fabrication and noticeable mechanical properties [62]. The monomer of polyamide 6 (PA6) is one of the most common commercial grades for molded parts, leading to high strength, high stiffness, good toughness, translucency, good fatigue life, and good abrasion resistance [63]. The reinforcement of PAs with short glass fibers increases strength, stiffness, heat distortion temperature, and abrasion resistance. In the case of PA6-unlike many polymers - this is achieved without any loss of impact strength, although strain at fracture may be reduced substantially [64]. In recent years, because of these favorable properties, short glass fiber reinforced PA 6 (SGFR-PA6) has found an increasing number of applications in the automotive [65] and railway industries [66]. Such applications entail the presence of notches (stress risers) that can threaten the structural integrity of the corresponding component. This demands a better understanding of the fracture behavior of SGFR-PA6 and the development and validation of tools for its structural integrity analysis in the presence of notches. With this aim, this article proposes the combination of the EMC and the TCD to estimate fracture loads in SGFR-PA6 single edged notched bending (SENB) fracture specimens containing $\mathrm{U}$-notches. The analysis combines different notch radii (from $0.25 \mathrm{~mm}$ up to $2.0 \mathrm{~mm}$ ) and different amounts of fiber content (from $0 \mathrm{wt} . \%$ up to $50 \mathrm{wt} . \%$ ). The article also verifies whether or not the simple direct combination of EMC and TCD (from now on, the EMC-TCD criterion) provides fracture load predictions with comparable accuracy to those provided by other methodologies (e.g., TCD, SED criterion, cohesive zone models, etc.). Here, it should be noted that most of the experimental results used for verifying the validity of EMC have been obtained by Torabi and co-researchers on thin rectangular plates subjected to remote tension and containing slender U-notches or $\mathrm{V}$-notches with low notch tip radius/notch length ratios (up to 0.07 ). Conversely, in the present work, the validity of EMC is verified for both slender and wide U-notches with notch tip radius/notch length ratios of up to 0.4 .

The section titled "Theoretical Background" provides a theoretical overview of the TCD, the EMC, and the EMC-TCD criterion. The section following the overview describes the experimental program, and the section titled "EMC-TCD Fracture Load Predictions" 
provides the fracture load predictions obtained by using the EMC-TCD criterion and the corresponding discussion. The last section gathers the key conclusions.

\section{Theoretical Background}

\section{THE TCD}

The TCD is, in essence, a set of methodologies, all of which use a material length parameter (the critical distance, $L$ ) when performing fracture or fatigue assessments [1]. The origin of the TCD can be found in the works of Neuber [67] and Peterson [68], but it has been in the last two decades that this theory has been thoroughly developed for the analysis of different types of materials, failure processes, and conditions (e.g., linear-elastic versus elastoplastic) [1].

The previously mentioned critical distance is generally referred to as $L$ and its expression, in fracture analyses, is as follows:

$$
L=\frac{1}{\pi}\left(\frac{K_{c}}{\sigma_{0}}\right)^{2}
$$

where $K_{c}$ is the material fracture toughness and $\sigma_{0}$ is a material strength parameter usually referred to as the inherent strength. This parameter is commonly larger than the material ultimate tensile strength $\left(\sigma_{u}\right)$, and in such cases, it requires calibration. Only in certain materials with fully linear-elastic behavior at both the micro and the macro scale (e.g., fracture of ceramics) does $\sigma_{0}$ coincide with $\sigma_{u}$, and the corresponding application of the TCD does not require calibration (i.e., $L$ is directly obtained from Eq 1 , the material fracture toughness and the material ultimate tensile strength).

Four of the methodologies included within the TCD are particularly simple when the elastic stress field around the stress concentration feature is known [1]: the point method (PM), the line method (LM), the area method (AM) and the volume method (VM).

The PM is the simplest methodology, and it proposes that fracture takes place when the stress at a distance of $L / 2$ from the defect tip reaches the inherent strength $\left(\sigma_{0}\right)$ :

$$
\sigma\left(\frac{L}{2}\right)=\sigma_{0}
$$

Alternatively, the LM proposes that fracture takes place when the average stress along a distance equal to $2 L$ (starting from the defect tip) reaches the inherent strength $\sigma_{0}$ :

$$
\frac{1}{2 L} \int_{0}^{2 L} \sigma(r) \mathrm{d} r=\sigma_{0}
$$

Both the AM and the VM also provide accurate predictions [1]. However, their application is generally more complex than the application of the PM or the LM. The AM uses the average stress over a certain area in the vicinity of the notch, whereas the VM considers the average stress within a particular control volume. Therefore, the results depend on the shape of the area or the volume chosen, respectively.

The TCD (and consequently, both the PM and the LM) allows the fracture assessment of components containing notches to be performed. However, for those materials on which $\sigma_{0}$ does not coincide with $\sigma_{u}$ (e.g., most polymers, metals, etc.), the former 
FIG. 1

Obtaining $L$ and $\sigma_{\circ}$ parameters based on the PM definition. The curves represent the stress fields at fracture for two notches with different notch radii.

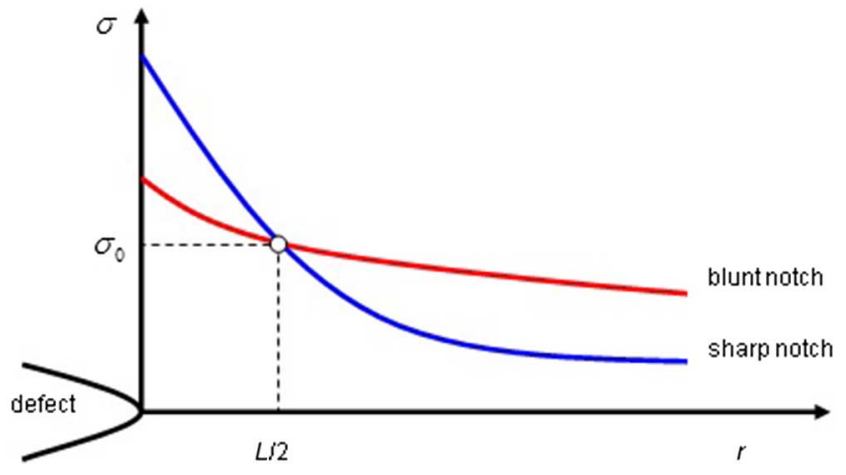

parameter requires calibration. This is generally performed by completing an experimental program on notched specimens with different notch radii (and defining $L$ as that value providing the best fit to the experimental results $[1,5]$ ), or by testing specimens with different notch radii and performing the corresponding FE simulation at failure (the superposition of the corresponding stress fields provides $L$ and $\sigma_{0}$, see Fig. 1) $[1,5,6]$. Whatever the case may be, the calibration process constitutes a major issue when applying the TCD methodologies and is a clear obstacle to their extensive application in industrial practice.

\section{THE EMC}

In 2012, Torabi [47] proposed, for the first time, the EMC in order to equate a real ductile material exhibiting elastic-plastic behavior with a virtual brittle material showing perfectly elastic behavior. He assumed the well-known power-law equation for the tensile stressstrain relationship in the plastic region (see Eq 4 in which the parameters $\sigma, \varepsilon_{P}, K$, and $n$ are the true stress, the true plastic strain, the strain-hardening coefficient, and the strain-hardening exponent, respectively) and computed the total SED for the real ductile material up to the peak point (i.e., the ultimate point). Then, it was assumed that the virtual brittle material absorbs the same amount of tensile SED for brittle fracture to take place. From this basic assumption, the tensile strength of the equivalent material was finally computed as a closed-form expression:

$$
\sigma=K \varepsilon_{P}^{n}
$$

A typical engineering stress-strain curve for a ductile material is represented in Fig. 2, in which the area under the curve is the SED. The total SED consists of the elastic and plastic components as follows:

$$
(S E D)_{\text {tot. }}=(S E D)_{e}+(S E D)_{p}=\frac{1}{2} \sigma_{y} \varepsilon_{y}+\int_{\varepsilon_{P}^{y}}^{\varepsilon_{P}} \sigma \mathrm{d} \varepsilon_{P}
$$

where $\sigma_{y}, \varepsilon_{y}$, and $\varepsilon_{P}^{y}$ are the yield strength, the elastic strain at yield point, and the true plastic strain at yield point, respectively. Considering Hooke's Law $\left(\sigma_{y}=E \varepsilon_{y}\right)$ and substituting Eq 4 into Eq 5 gives the following equation: 
FIG. 2

Schematic of a typical stressstrain curve for a ductile material.

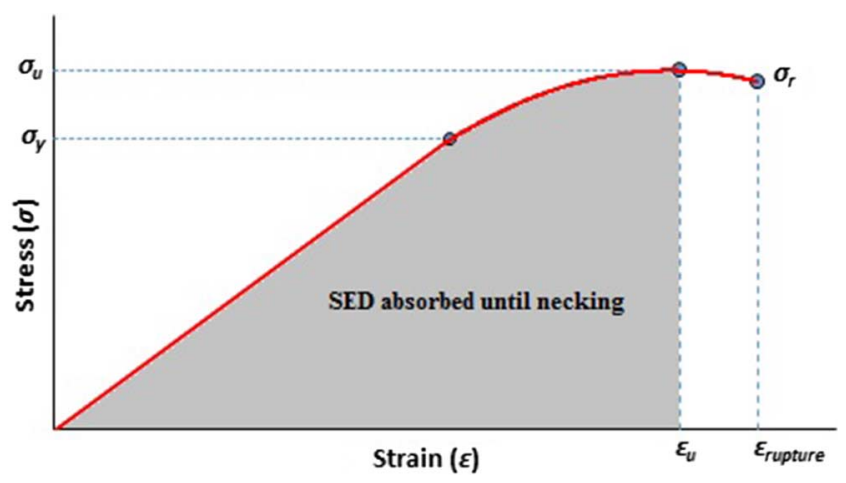

$$
(S E D)_{\text {tot. }}=\frac{\sigma_{y}^{2}}{2 E}+\int_{\varepsilon_{P}^{y}}^{\varepsilon_{P}} K \varepsilon_{P}^{n} d \varepsilon_{P}=\frac{\sigma_{y}^{2}}{2 E}+\frac{K}{n+1}\left[\left(\varepsilon_{P}\right)^{n+1}-\left(\varepsilon_{P}^{y}\right)^{n+1}\right]
$$

The true plastic strain at yield point $\left(\varepsilon_{P}^{y}\right)$ is simply considered to be equal to 0.002 (i.e., $0.2 \%$ offset) and hence

$$
(S E D)_{\text {tot. }}=\frac{\sigma_{y}^{2}}{2 E}+\frac{K}{n+1}\left[\left(\varepsilon_{P}\right)^{n+1}-(0.002)^{n+1}\right]
$$

The crack initiation in the ductile material (i.e., the necking instance) will occur just when the ultimate load is reached. Thus, the total SED (Eq 7) should be computed until this point. In other words, the plastic strain $\varepsilon_{P}$ in Eq 7 is replaced with the true plastic strain at maximum load $\varepsilon_{u, \text { True }}$ as follows:

$$
(S E D)_{\text {necking }}=\frac{\sigma_{y}^{2}}{2 E}+\frac{K}{n+1}\left[\left(\varepsilon_{u, \text { True }}\right)^{n+1}-(0.002)^{n+1}\right]
$$

Fig. 3 depicts a typical stress-strain curve for the virtual brittle material with a perfectly linear elastic behavior. It can be simply obtained from this figure that the total strain energy absorbed until fracture is $\sigma_{f}^{*} \varepsilon_{f}^{*} / 2$, where $\sigma_{f}^{*}$ and $\varepsilon_{\mathrm{f}}^{*}$ are the tensile strength and the strain at fracture for the virtual brittle material, respectively. Because the basic assumption of EMC is that both the real ductile and virtual brittle materials have the same Young's modulus $(E)$ and K-based fracture toughness $\left(K_{c}\right)$, the SED for the equivalent material until fracture can be written as the following:

$$
(S E D)_{E M}=\frac{\sigma_{f}^{* 2}}{2 E}
$$

As mentioned previously, the SED values for the real ductile and virtual brittle materials are the same in accordance with EMC. Hence, setting Eqs 8 and 9 to be equal results in the following equation: 
FIG. 3

Schematic of the stress-strain curve for the equivalent brittle material.

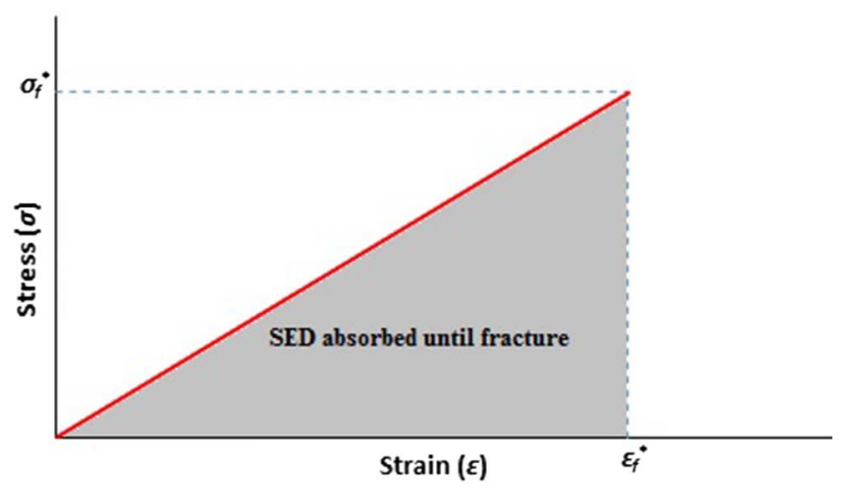

$$
\frac{\sigma_{f}^{*}}{2 E}=\frac{\sigma_{y}^{2}}{2 E}+\frac{K}{n+1}\left[\left(\varepsilon_{u, \text { True }}\right)^{n+1}-(0.002)^{n+1}\right]
$$

Eventually, the following closed-form expression is proposed by EMC for calculating the $\sigma_{f}^{*}$ :

$$
\sigma_{f}^{*}=\sqrt{\sigma_{y}^{2}+\frac{2 E K}{n+1}\left[\left(\varepsilon_{u, T r u e}\right)^{n+1}-(0.002)^{n+1}\right]}
$$

where $\varepsilon_{u \text {,True }}$ (the true plastic strain at peak point) can be computed from the $\varepsilon_{u}$ (engineering plastic strain at peak point) by the following expression: $\varepsilon_{u, T r u e}=\ln \left(1+\varepsilon_{u}\right)$.

The $\sigma_{f}^{*}$ computed from Eq 11 together with a valid fracture toughness can be conveniently utilized in various brittle fracture criteria (e.g., TCD) for theoretically predicting the crack initiation in ductile components weakened by a notch.

In the following sections, the experimental program is presented and the corresponding results are used to verify the validity of the EMC-TCD criterion for the prediction of fracture loads on SGFR-PA6.

\section{Experimental Program}

The SGFR-PA6 (Durethan, Lanxess, Germany) was characterized mechanically for four different amounts of fiber contents $(5,10,30$, and $50 \mathrm{wt} . \%)$. The whole experiment was composed of 108 specimens (see Fig. 4) that were fabricated with an Arburg Allrounder $221 \mathrm{~K}$ injection molding machine (Arburg, Loßburg, Germany) with a single steel mold

\section{FIG. 4}

Tensile specimen dimensions $(\mathrm{mm})$.

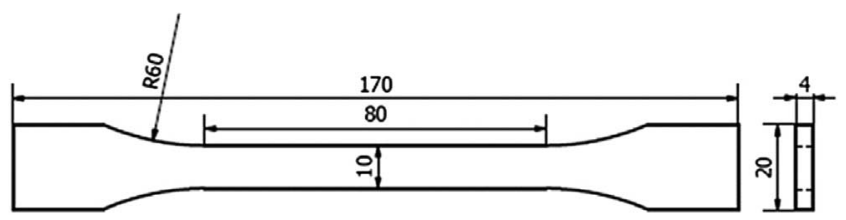


FIG. 5

SENB test specimen dimensions ( $\mathrm{mm}$ ), with $\rho$ varying from $\mathrm{O} \mathrm{mm}$ to $2 \mathrm{~mm}$.

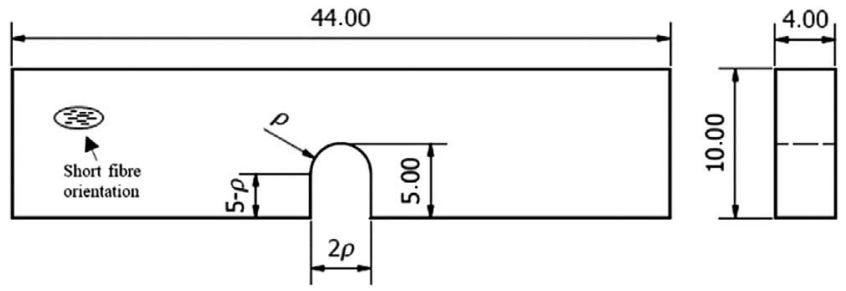

containing two standard tensile specimens, and the fibers were oriented in the longitudinal direction of the specimen. Eight specimens were directly used to complete eight tensile tests (two per fiber content). Afterwards, 100 fracture tests (5 per combination of the 5 notch radii and the 4 fiber contents) were conducted on SENB fracture specimens (see Fig. 5) extracted from the central part of the remaining 100 injected specimens. The fracture specimens contained crack-like defects and U-shaped notches with notch radii of $0.25,0.50,1.0$, and $2.0 \mathrm{~mm}$. The specimens were dried in an oven at $100^{\circ} \mathrm{C}$ before testing (tensile or fracture) in order to eliminate any trace of moisture.

Table 1 gathers the main characteristics of the used glass fiber. Tensile tests, which are necessary for the application of EMC, were performed following ASTM D638, Standard Test Method for Tensile Properties of Plastics [69], while fracture tests were performed following ASTM D5045, Standard Test Methods for Plane-Strain Fracture Toughness and Strain Energy Release Rate of Plastic Material [70]. Details on the experimental procedures are gathered in Ibáñez-Gutiérrez et al. [8].

Fig. 6 shows the obtained stress-strain curves (engineering variables) used in this work. It can be observed how the nonlinear behavior becomes more evident as the glass fiber content increases. The main material parameters, obtained as the average values derived from the two tensile tests performed per fiber content, are gathered in Table 2, where $E$ is the Young's modulus, $\sigma_{0.2}$ is the $0.2 \%$ proof strength, $\sigma_{u}$ is the ultimate tensile strength, and $e_{\max }$ is the strain under maximum load. These curves are used in the section titled "EMC-TCD Fracture Load Predictions" to derive $\sigma_{f}^{*}$ and, thus, the tensile behavior of the equivalent linear-elastic material.

Concerning the fracture tests, a total of twenty sets of tests were performed that corresponded to each combination of the four fiber contents $(5,10,30$, and $50 \%)$ and the five notch radii (from $0 \mathrm{~mm}$ to $2.0 \mathrm{~mm}$ ), each set being tentatively composed of five tests. The notches were introduced by machining, except for crack-like defects that were generated by sawing a razor blade across an initial notch root [70]. Tables 3-6 gather the different tests with the corresponding geometries and the resulting fracture loads. Details of the experimental procedure and the obtained load-displacement curves may be consulted in Ref. [8], with some examples being shown in Fig. 7. It can be observed how there

TABLE 1

E-glass fiber parameters. $L_{f}$ : fiber length; $\varnothing$ : diameter; $\sigma_{u}$ : ultimate tensile strength; $E$ : elastic modulus; $\rho$ : density.

\begin{tabular}{lcccr}
\hline$L_{f}, \mu \mathrm{m}$ & $\varnothing, \mu \mathrm{m}$ & $\sigma_{\mathrm{u}}, \mathrm{MPa}$ & $E, \mathrm{GPa}$ & $\rho, \mathrm{g} / \mathrm{cm}^{3}$ \\
\hline 300 & 10 & 3450 & 72.50 & 2.60 \\
\hline
\end{tabular}


FIG. 6

Tensile curves obtained for the different amounts of fiber content (wt. \%)

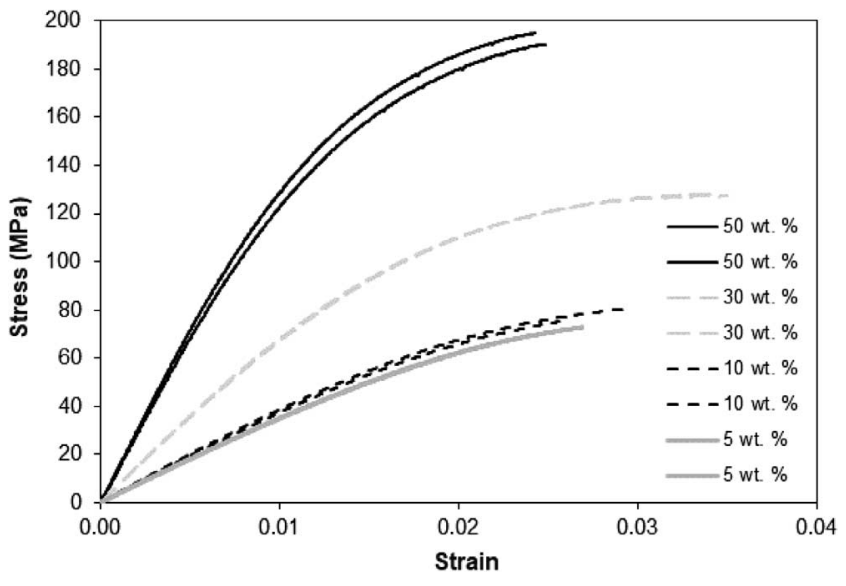

TABLE 2

SGFR-PA6 tensile parameters. E: elastic modulus; $\sigma_{0.2}: 0.2 \%$ proof stress; $\sigma_{u}$ : ultimate tensile strength; $e_{\text {max }}$ : strain under maximum load.

\begin{tabular}{lccccc}
\hline Fiber Content, \% & Test & $E, \mathrm{GPa}$ & $\sigma_{0.2}, \mathrm{MPa}$ & $\sigma_{u}, \mathrm{MPa}$ & $e_{\max }, \%$ \\
\hline 0 & 1 & 2.80 & 55.7 & 55.7 & 2.17 \\
& 2 & 2.90 & 52.7 & 52.7 & 1.96 \\
5 & 1 & 3.30 & 67.0 & 71.2 & 2.61 \\
& 2 & 3.30 & 66.8 & 72.9 & 2.72 \\
10 & 1 & 3.60 & 70.7 & 80.8 & 3.02 \\
& 2 & 3.50 & 69.6 & 75.5 & 2.65 \\
30 & 1 & 6.40 & 105.5 & 128.4 & 3.55 \\
& 2 & 6.50 & 105.2 & 127.6 & 3.57 \\
50 & 1 & 13.0 & 163.4 & 195.1 & 2.45 \\
& 2 & 12.2 & 158.9 & 190.5 & 2.49 \\
\hline
\end{tabular}

is a certain nonlinearity in the curves obtained in those specimens with a higher fiber content, although most of the fracture tests have provided linear load-displacement curves and this loss of linearity is noticeably less pronounced than that observed in the tensile tests. One of the tests (specimen 30-0.5-4) was not valid.

Finally, for each fiber content, the results obtained in the five cracked specimens have been used to derive the corresponding material fracture toughness $\left(K_{c}\right)$ [8], which is easily derived from the critical load and both the specimen and crack geometries (SENB specimen) [70]:

$$
K_{c}=\left(\frac{P_{\max }}{B \cdot W^{0.5}}\right) \cdot 6 \cdot\left(\frac{a}{W}\right)^{0.5}\left(\frac{1.99-\left(\frac{a}{W}\right) \cdot\left(1-\frac{a}{W}\right) \cdot\left(2.15-3.93\left(\frac{a}{W}\right)+2.7\left(\frac{a}{W}\right)^{2}\right)}{\left(1+2 \frac{a}{W}\right) \cdot\left(1-\frac{a}{W}\right)^{1.5}}\right)
$$

The corresponding average values of $K_{c}$ are shown in Table 7, where a pronounced effect of the fiber content on this material property can be observed (e.g., $K_{c}$ is 4.66 times greater with 50 wt.\% than with 5 wt.\%). 


\section{TABLE 3}

Description of SGFR-PA6 (5 wt.\%) specimens, experimental results $\left(P_{\text {exp }}\right)$, average experimental results $\left(P_{\text {exp,av }}\right)$, and fracture load estimations $\left(P_{\text {est }}^{P M}(E M C-T C D[P M])\right.$ and $P_{\text {est }}{ }^{L M}$ (EMC-TCD $\left.[L M]\right)$ ). The values in parentheses represent the deviation of the predictions.

\begin{tabular}{|c|c|c|c|c|c|c|}
\hline Notch Radius $\rho, \mathrm{mm}$ & Specimen & Notch Length $a, \mathrm{~mm}$ & Max. Load $P_{\text {exp }}, \mathrm{N}$ & $P_{\text {exp,av }}, \mathrm{N}$ & $P_{e s t}^{P M}, \mathrm{~N}$ (deviation) & $P_{\text {est }}^{L M}, \mathrm{~N}$ (deviation) \\
\hline 0.00 & $5-0-1$ & 4.65 & 100.50 & 76.88 & - & - \\
\hline 0.00 & $5-0-2$ & 4.60 & 69.60 & & & \\
\hline 0.00 & $5-0-3$ & 4.70 & 73.30 & & & \\
\hline 0.00 & $5-0-4$ & 4.50 & 72.00 & & & \\
\hline 0.00 & $5-0-5$ & 4.80 & 69.00 & & & \\
\hline 0.25 & $5-0.25-1$ & 5.00 & 83.80 & 82.10 & $69.76(-15.03 \%)$ & $82.55(+0.55 \%)$ \\
\hline 0.25 & $5-0.25-2$ & 5.00 & 82.20 & & & \\
\hline 0.25 & $5-0.25-3$ & 5.00 & 111.00 & & & \\
\hline 0.25 & $5-0.25-4$ & 5.00 & 56.40 & & & \\
\hline 0.25 & $5-0.25-5$ & 5.00 & 77.10 & & & \\
\hline 0.5 & $5-0.5-1$ & 5.00 & 100.10 & 97.56 & $82.07(-15.88 \%)$ & $94.22(-3.42 \%)$ \\
\hline 0.5 & $5-0.5-2$ & 5.00 & 108.40 & & & \\
\hline 0.5 & $5-0.5-3$ & 5.00 & 96.00 & & & \\
\hline 0.5 & $5-0.5-4$ & 5.00 & 100.60 & & & \\
\hline 0.5 & $5-0.5-5$ & 5.00 & 82.70 & & & \\
\hline 1.00 & $5-1-1$ & 5.00 & 120.70 & 113.46 & $103.68(-8.62 \%)$ & $114.03(+0.50 \%)$ \\
\hline 1.00 & $5-1-2$ & 5.00 & 99.30 & & & \\
\hline 1.00 & $5-1-3$ & 5.00 & 119.10 & & & \\
\hline 1.00 & $5-1-4$ & 5.00 & 122.20 & & & \\
\hline 1.00 & $5-1-5$ & 5.00 & 106.00 & & & \\
\hline 2.00 & $5-2-1$ & 5.00 & 151.60 & 137.84 & $137.64(-0.15 \%)$ & $145.79(+5.77 \%)$ \\
\hline 2.00 & $5-2-2$ & 5.00 & 135.40 & & & \\
\hline 2.00 & $5-2-3$ & 5.00 & 126.60 & & & \\
\hline 2.00 & $5-2-4$ & 5.00 & 149.70 & & & \\
\hline 2.00 & $5-2-5$ & 5.00 & 125.90 & & & \\
\hline
\end{tabular}

\section{TABLE 4}

Description of SGFR-PA6 (10 wt. \%) specimens, experimental results $\left(P_{\text {exp }}\right)$, average experimental results $\left(P_{\text {exp.av }}\right)$, and fracture load estimations $\left(P_{\text {est }}^{P M}(E M C-T C D[P M])\right.$ and $\left.P_{\text {est }}{ }^{L M}(E M C-T C D[L M])\right)$. The values in parentheses represent the deviation of the predictions.

\begin{tabular}{|c|c|c|c|c|c|c|}
\hline Notch Radius $\rho, \mathrm{mm}$ & Specimen & Notch Length $a, \mathrm{~mm}$ & Max. Load $P_{\text {exp }}, \mathrm{N}$ & $P_{\text {exp }, a v}, \mathrm{~N}$ & $P_{e s t}^{P M}, \mathrm{~N}$ (deviation) & $P_{e s t}^{L M}, \mathrm{~N}$ (deviation) \\
\hline 0.00 & $10-0-1$ & 4.20 & 117.50 & 93.50 & - & - \\
\hline 0.00 & $10-0-2$ & 4.25 & 107.20 & & & \\
\hline 0.00 & $10-0-3$ & 4.60 & 70.20 & & & \\
\hline 0.00 & $10-0-4$ & 4.60 & 76.70 & & & \\
\hline 0.00 & $10-0-5$ & 4.90 & 95.90 & & & \\
\hline 0.25 & $10-0.25-1$ & 5.00 & 93.10 & 93.84 & $80.26(-14.47 \%)$ & $95.08(+1.32 \%)$ \\
\hline 0.25 & $10-0.25-2$ & 5.00 & 105.20 & & & \\
\hline 0.25 & $10-0.25-3$ & 5.00 & 104.50 & & & \\
\hline 0.25 & $10-0.25-4$ & 5.00 & 87.80 & & & \\
\hline 0.25 & $10-0.25-5$ & 5.00 & 78.60 & & & \\
\hline 0.5 & $10-0.5-1$ & 5.00 & 116.20 & 104.10 & $93.88(-9.82 \%)$ & $108.08(+3.82 \%)$ \\
\hline 0.5 & $10-0.5-2$ & 5.00 & 102.10 & & & \\
\hline 0.5 & $10-0.5-3$ & 5.00 & 93.40 & & & \\
\hline 0.5 & $10-0.5-4$ & 5.00 & 111.10 & & & \\
\hline 0.5 & $10-0.5-5$ & 5.00 & 97.70 & & & \\
\hline 1.00 & $10-1-1$ & 5.00 & 124.10 & 125.26 & $118.07(-5.74 \%)$ & $130.26(+3.99 \%)$ \\
\hline 1.00 & $10-1-2$ & 5.00 & 116.50 & & & \\
\hline
\end{tabular}


TABLE 4 Continued

\begin{tabular}{|c|c|c|c|c|c|c|}
\hline Notch Radius $\rho, \mathrm{mm}$ & Specimen & Notch Length $a, \mathrm{~mm}$ & Max. Load $P_{\text {exp }}, \mathrm{N}$ & $P_{\text {exp,av }}, \mathrm{N}$ & $P_{e s t}^{P M}, \mathrm{~N}$ (deviation) & $P_{\text {est }}{ }^{L M}, \mathrm{~N}$ (deviation) \\
\hline 1.00 & $10-1-3$ & 5.00 & 141.00 & \multirow{8}{*}{161.52} & \multirow{8}{*}{$156.29(-3.74 \%)$} & \multirow{8}{*}{$165.95(+2.74 \%)$} \\
\hline 1.00 & $10-1-4$ & 5.00 & 125.00 & & & \\
\hline 1.00 & $10-1-5$ & 5.00 & 119.70 & & & \\
\hline 2.00 & $10-2-1$ & 5.00 & 173.80 & & & \\
\hline 2.00 & $10-2-2$ & 5.00 & 166.70 & & & \\
\hline 2.00 & $10-2-3$ & 5.00 & 167.30 & & & \\
\hline 2.00 & $10-2-4$ & 5.00 & 146.40 & & & \\
\hline 2.00 & $10-2-5$ & 5.00 & 153.40 & & & \\
\hline
\end{tabular}

\section{TABLE 5}

Description of SGFR-PA6 (30 wt. \%) specimens, experimental results $\left(P_{\text {exp }}\right)$, average experimental results $\left(P_{\text {exp.av }}\right)$, and fracture load estimations $\left(P_{\text {est }}^{P M}(E M C-T C D[P M])\right.$ and $P_{\text {est }}{ }^{L M}$ (EMC-TCD [LM])). The values in parentheses represent the deviation of the predictions.

\begin{tabular}{|c|c|c|c|c|c|c|}
\hline Notch Radius $\rho, \mathrm{mm}$ & Specimens & Notch Length $a, \mathrm{~mm}$ & Max. Load $P_{\text {exp }}, \mathrm{N}$ & $P_{\text {exp, av }}, \mathrm{N}$ & $P_{\text {est }}{ }^{P M}, \mathrm{~N}$ (deviation) & $P_{e s t}^{L M}, \mathrm{~N}$ (deviation) \\
\hline 0.00 & $30-0-1$ & 4.48 & 253.50 & 199.30 & - & - \\
\hline 0.00 & $30-0-2$ & 4.70 & 195.50 & & & \\
\hline 0.00 & $30-0-3$ & 4.80 & 195.70 & & & \\
\hline 0.00 & $30-0-4$ & 4.57 & 171.70 & & & \\
\hline 0.00 & $30-0-5$ & 4.75 & 180.10 & & & \\
\hline 0.25 & $30-0.25-1$ & 5.00 & 237.80 & 216.46 & $175.45(-18.95 \%)$ & $208.32(-3.76 \%)$ \\
\hline 0.25 & $30-0.25-2$ & 5.00 & 220.20 & & & \\
\hline 0.25 & $30-0.25-3$ & 5.00 & 202.50 & & & \\
\hline 0.25 & $30-0.25-4$ & 5.00 & 216.40 & & & \\
\hline 0.25 & $30-0.25-5$ & 5.00 & 205.40 & & & \\
\hline 0.5 & $30-0.5-1$ & 5.00 & 207.10 & 238.65 & $201.60(-15.52 \%)$ & $234.03(-1.94 \%)$ \\
\hline 0.5 & $30-0.5-2$ & 5.00 & 252.40 & & & \\
\hline 0.5 & $30-0.5-3$ & 5.00 & 251.80 & & & \\
\hline 0.5 & $30-0.5-4$ & - & - & & & \\
\hline 0.5 & $30-0.5-5$ & 5.00 & 243.30 & & & \\
\hline 1.00 & $30-1-1$ & 5.00 & 231.60 & 264.04 & $250.00(-5.32 \%)$ & $276.41(+4.68 \%)$ \\
\hline 1.00 & $30-1-2$ & 5.00 & 251.50 & & & \\
\hline 1.00 & $30-1-3$ & 5.00 & 287.90 & & & \\
\hline 1.00 & $30-1-4$ & 5.00 & 302.60 & & & \\
\hline 1.00 & $30-1-5$ & 5.00 & 246.60 & & & \\
\hline 2.00 & $30-2-1$ & 5.00 & 305.80 & 288.20 & $327.88(+13.77 \%)$ & $350.72(+21.69 \%)$ \\
\hline 2.00 & $30-2-2$ & 5.00 & 284.20 & & & \\
\hline 2.00 & $30-2-3$ & 5.00 & 269.00 & & & \\
\hline 2.00 & $30-2-4$ & 5.00 & 263.70 & & & \\
\hline 2.00 & $30-2-5$ & 5.00 & 318.30 & & & \\
\hline
\end{tabular}

\section{TABLE 6}

Description of SGFR-PA6 (50 wt. \%) specimens, experimental results $\left(P_{\text {exp }}\right)$, average experimental results $\left(P_{\text {exp,av }}\right)$, and fracture load estimations $\left(P_{\text {est }}^{P M}\right.$ (EMC-TCD [PM]) and $P_{\text {est }}{ }^{L M}$ (EMC-TCD [LM])). The values in parentheses represent the deviation of the predictions.

\begin{tabular}{|c|c|c|c|c|c|c|}
\hline Notch Radius $\rho, \mathrm{mm}$ & Specimens & Notch Length $a, \mathrm{~mm}$ & Max. Load $P_{\text {exp }}, \mathrm{N}$ & $P_{\text {exp,av }}, \mathrm{N}$ & $P_{\text {est }}^{P M}, \mathrm{~N}$ (deviation) & $P_{\text {est }}^{L M}, \mathrm{~N}$ (deviation) \\
\hline 0.00 & $50-0-1$ & 4.55 & 348.70 & 349.62 & - & - \\
\hline 0.00 & $50-0-2$ & 4.75 & 351.80 & & & \\
\hline 0.00 & $50-0-3$ & 4.90 & 331.80 & & & \\
\hline 0.00 & $50-0-4$ & 4.80 & 346.40 & & & \\
\hline 0.00 & $50-0-5$ & 4.70 & 369.40 & & & \\
\hline
\end{tabular}




\begin{tabular}{|c|c|c|c|c|c|c|}
\hline Notch Radius $\rho, \mathrm{mm}$ & Specimens & Notch Length $a, \mathrm{~mm}$ & Max. Load $P_{\text {exp }}, \mathrm{N}$ & $P_{\text {exp,av }}, \mathrm{N}$ & $P_{\text {est }}^{P M}, \mathrm{~N}$ (deviation) & $P_{\text {est }}{ }^{L M}, \mathrm{~N}$ (deviation) \\
\hline 0.25 & $50-0.25-1$ & 5.00 & 322.00 & 337.00 & $300.11(-10.95 \%)$ & $354.27(+5.12 \%)$ \\
\hline 0.25 & $50-0.25-2$ & 5.00 & 338.00 & & & \\
\hline 0.25 & $50-0.25-3$ & 5.00 & 329.40 & & & \\
\hline 0.25 & $50-0.25-4$ & 5.00 & 360.60 & & & \\
\hline 0.25 & $50-0.25-5$ & 5.00 & 335.00 & & & \\
\hline 0.5 & $50-0.5-1$ & 5.00 & 367.40 & 371.38 & $323.59(-12.87 \%)$ & $383.35(+3.22 \%)$ \\
\hline 0.5 & $50-0.5-2$ & 5.00 & 367.90 & & & \\
\hline 0.5 & $50-0.5-3$ & 5.00 & 364.60 & & & \\
\hline 0.5 & $50-0.5-4$ & 5.00 & 376.90 & & & \\
\hline 0.5 & $50-0.5-5$ & 5.00 & 380.10 & & & \\
\hline 1.00 & $50-1-1$ & 5.00 & 389.70 & 394.38 & $378.41(-4.05 \%)$ & $435.73(+10.48 \%)$ \\
\hline 1.00 & $50-1-2$ & 5.00 & 394.50 & & & \\
\hline 1.00 & $50-1-3$ & 5.00 & 402.40 & & & \\
\hline 1.00 & $50-1-4$ & 5.00 & 395.70 & & & \\
\hline 1.00 & $50-1-5$ & 5.00 & 389.60 & & & \\
\hline 2.00 & $50-2-1$ & 5.00 & 432.30 & 426.20 & $475.87(+11.65 \%)$ & $525.04(+23.19 \%)$ \\
\hline 2.00 & $50-2-2$ & 5.00 & 414.20 & & & \\
\hline 2.00 & $50-2-3$ & 5.00 & 426.50 & & & \\
\hline 2.00 & $50-2-4$ & 5.00 & 431.00 & & & \\
\hline 2.00 & $50-2-5$ & 5.00 & 427.00 & & & \\
\hline
\end{tabular}

\section{EMC-TCD Fracture Load Predictions}

\section{CALIBRATION OF THE EQUIVALENT MATERIAL}

The tensile curves shown in Fig. 6 have been used to define, for each fiber content, the equivalent linear-elastic material following the EMC formulation gathered in the section titled "The EMC." The equivalent materials maintain the same elastic modulus as that observed in the corresponding real material (average values of those shown in Table 2), but the tensile strength of the equivalent materials $\left(\sigma_{f}^{*}\right)$ may be significantly higher than that observed experimentally (1.19 times greater for 5 wt. \% fiber content, 1.25 times greater for $10 \mathrm{wt} . \%, 1.58$ times greater for $30 \mathrm{wt} . \%$, and 1.44 times greater for $50 \mathrm{wt} . \%$; see Tables 2 and 7). These two parameters ( $E$ and $\left.\sigma_{f}^{*}\right)$ are enough to define the tensile behavior of the four-resulting equivalent materials and allow the fracture behavior of the real (non-fully linear) materials to be determined based on linear-elastic assumptions.

\section{DERIVATION OF FRACTURE LOAD PREDICTIONS}

Once the material properties of the equivalent linear-elastic materials are known, the linear elastic formulation of the TCD can be directly applied. Assuming a perfectly linear-elastic behavior implies that the value of the critical distance $(L)$ can be directly obtained from Eq 1 and that the inherent strength $\left(\sigma_{0}\right)$ is equal to the tensile strength of the equivalent material $\left(\sigma_{f}^{*}\right)$. Thus, the calibration process (required to define $L$ (and $\sigma_{0}$ ) in the real ductile material) is avoided. This process is traditionally performed through fracture tests on notched specimens or through a combination of fracture tests and FE modeling. The different values of $L$ are given in Table 7. It can be seen how $L$ slightly increases for fiber contents from $5 \mathrm{wt} . \%$ up to $30 \mathrm{wt} . \%$ and how it experiences a greater increase for a $50 \mathrm{wt} . \%$ fiber content.

As stated previously, one of the main aims of this research is to provide a simple procedure for the failure assessment of notched components. Therefore, instead of using 
FIG. 7

Load-displacement curve obtained in some SGFR-PA6 specimens for a fiber content of 10 wt. \% (a) and for a notch radius of $0.50 \mathrm{~mm}(\mathrm{~b})$.

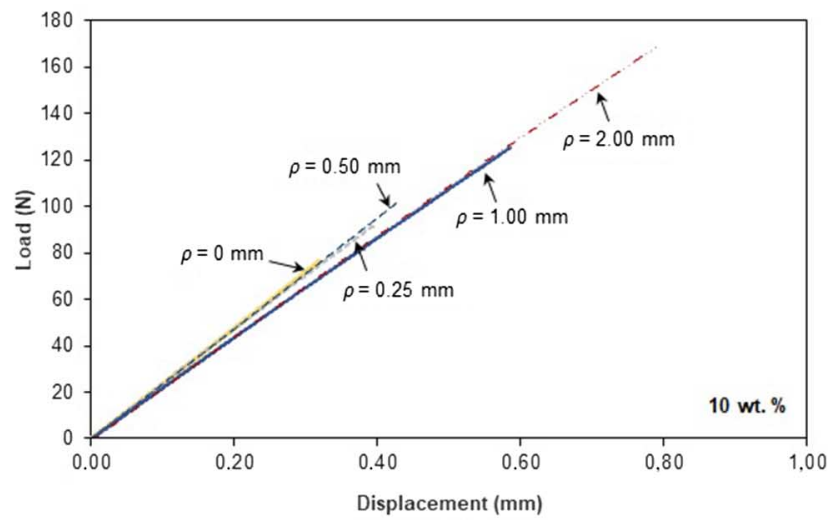

(a)

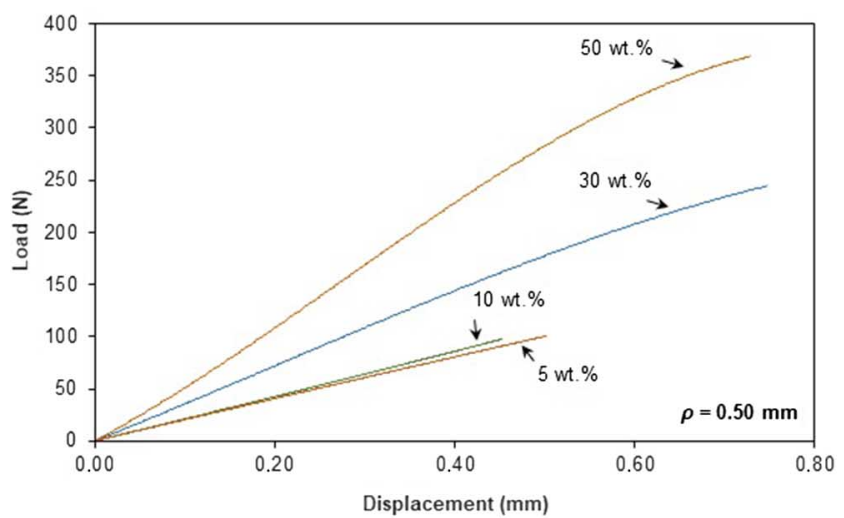

(b)

TABLE 7

$K_{c}$ (including the standard deviation, Stv $\left(K_{c}\right)$ ), $\sigma_{f}^{*}$, and resulting $L$ values for the different amounts of fiber content.

\begin{tabular}{lcccc}
\hline Fiber Content & $K_{c}, \mathrm{MPa} \cdot \mathrm{m}^{1 / 2}$ & $\mathrm{Stv}\left(K_{c}\right), \mathrm{MPa} \cdot \mathrm{m}^{1 / 2}$ & $\sigma_{f}^{\star}, \mathrm{MPa}$ & $L, \mathrm{~mm}$ \\
\hline 5 wt. $\%$ & 1.84 & 0.32 & 86.3 & 0.144 \\
10 wt. $\%$ & 2.13 & 0.38 & 97.7 & 0.151 \\
30 wt. $\%$ & 4.77 & 0.65 & 202.6 & 0.176 \\
50 wt. $\%$ & 8.59 & 0.32 & 278.3 & 0.303 \\
\hline
\end{tabular}

FE modeling to determine the fracture load predictions, it is proposed to use well-known accurate analytical solutions. In the case of U-shaped notches, the Creager-Paris solution [71] for the stress field at the notch tip is generally accepted [1]. Creager and Paris propose a stress field ahead of the notch tip that it is equal to that ahead of the crack tip but is displaced at a distance equal to $\rho / 2$ along the $\mathrm{x}$-axis:

$$
\sigma(r)=\frac{K_{I}}{\sqrt{\pi}} \frac{2(r+\rho)}{(2 r+\rho)^{\frac{3}{2}}}
$$


$K_{I}$ is the mode I stress intensity factor in cracked conditions, $\rho$ is the notch radius, and $r$ is the distance existing from the notch tip to the point being assessed.

Eq 13 can be used to estimate critical loads through the TCD. If the PM is considered, the corresponding fracture condition for a particular notch radius $(\rho)$ would be as follows [1]:

$$
\sigma(L / 2)=\frac{K_{I}}{\sqrt{\pi}} \frac{2(L / 2+\rho)}{(L+\rho)^{\frac{3}{2}}}=\sigma_{f}^{*}
$$

Consequently, Eq 14 allows the value of $K_{I}$ at fracture to be obtained. Once $K_{I}$ is known, the estimation of the critical load $\left(P_{e s t}^{P M}\right)$ is easily derived from the following equation [70]:

$$
K_{I}=\left(\frac{P_{e s t}^{P M}}{B \cdot W^{0.5}}\right) \cdot 6 \cdot\left(\frac{a}{W}\right)^{0.5}\left(\frac{1.99-\left(\frac{a}{W}\right) \cdot\left(1-\frac{a}{W}\right) \cdot\left(2.15-3.93\left(\frac{a}{W}\right)+2.7\left(\frac{a}{W}\right)^{2}\right)}{\left(1+2 \frac{a}{W}\right) \cdot\left(1-\frac{a}{W}\right)^{1.5}}\right)
$$

If the LM is considered, it is necessary to determine the average stress $\left(\sigma_{a v}\right)$ over the distance $r=0$ to $2 L$, giving [1]

$$
\sigma_{a v}=\frac{K_{I}}{2 L \sqrt{2 \pi}}\left(2 \sqrt{\frac{\rho}{2}+2 L}-\frac{\rho}{\sqrt{\frac{\rho}{2}+2 L}}\right)
$$

Establishing the fracture condition provided by the $\mathrm{LM}, K_{I}$ is simply obtained from Eq 17:

$$
\frac{K_{I}}{2 L \sqrt{2 \pi}}\left(2 \sqrt{\frac{\rho}{2}+2 L}-\frac{\rho}{\sqrt{\frac{\rho}{2}+2 L}}\right)=\sigma_{f}^{*}
$$

Once $K_{I}$ is known, the estimations of the fracture loads $\left(P_{e s t}^{L M}\right)$ are straightforward [70]:

$$
K_{I}=\left(\frac{P_{e s t}^{L M}}{B \cdot W^{0.5}}\right) \cdot 6 \cdot\left(\frac{a}{W}\right)^{0.5}\left(\frac{1.99-\left(\frac{a}{W}\right) \cdot\left(1-\frac{a}{W}\right) \cdot\left(2.15-3.93\left(\frac{a}{W}\right)+2.7\left(\frac{a}{W}\right)^{2}\right)}{\left(1+2 \frac{a}{W}\right) \cdot\left(1-\frac{a}{W}\right)^{1.5}}\right)
$$

Here, it should be noted that the whole process only requires the calibration of the equivalent material, which is easily completed from a tensile test, with no need for FE modeling or calibration fracture tests.

\section{RESULTS AND DISCUSSION}

Tables 3-6 show the fracture load predictions obtained through the application of the EMC and the TCD (both the PM and the LM methodologies). Figs. 8-11 show the same results graphically.

It can be observed that the predictions provided when using the EMC-TCD methodology are mostly located within the $\pm 20 \%$ error lines, clearly capturing the physics of the notch effect in these particular materials. More precisely, the predictions obtained when applying the LM are more accurate than those obtained when using the PM: when comparing the predictions with the average experimental values, the LM generally 
FIG. 8

Comparison between fracture load predictions and experimental fracture loads: (a) individual tests; (b) average values for each set of tests (notch radius). SGFR-PA6 specimens for a fiber content of 5 wt. \%.

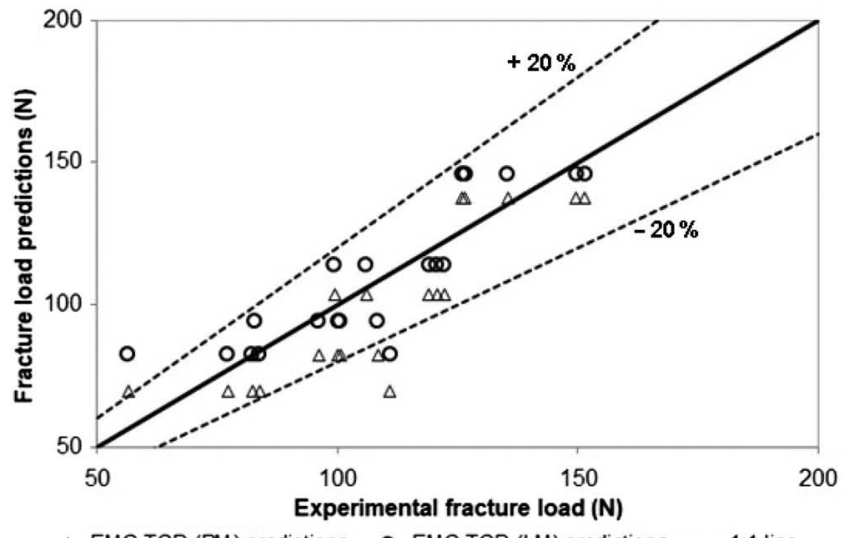

$\triangle$ EMC-TCD (PM) predictions O EMC-TCD (LM) predictions - 1:1 line

(a)

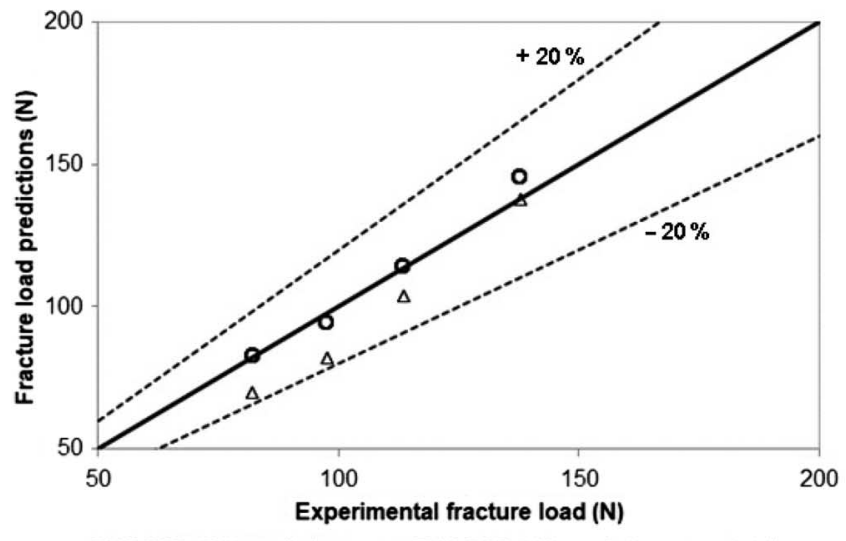

$\triangle$ EMC-TCD (PM) predictions O EMC-TCD (LM) predictions — 1:1 line (b)

provides errors within $\pm 5 \%$, except for the cases of $30 \mathrm{wt} . \%$ and $50 \mathrm{wt} . \%$ fiber contents with a $2.0-\mathrm{mm}$ notch radius, for which the methodology provides overestimations of $+21.7 \%$ and $+23.2 \%$, respectively. In the case of the PM, the predictions tend to underestimate the experimental critical loads. When considering average experimental values, it has generally provided conservative predictions, except for the cases (again) of $30 \mathrm{wt} . \%$ and 50 wt.\% fiber contents with a $2.0-\mathrm{mm}$ notch radius, for which the PM has provided overestimations of $+13.7 \%$ and $+11.6 \%$, respectively. In any case, all the predictions are located within the $\pm 20 \%$ lines. Therefore, it should be noted that for a combination of high fiber contents (i.e., $30 \mathrm{wt} . \%$ and $50 \mathrm{wt} . \%$ ) and a high notch radius (i.e., $1.00 \mathrm{~mm}$ and $2.00 \mathrm{~mm}$ ), which generates a higher nonlinear behavior, the accuracy of the predictions seems to depend on the notch radius (Figs. 10 and 11).

The reason why the predictions for both the LM and the PM tend to deviate most for a notch radius of $2.0 \mathrm{~mm}$ and high fiber contents may be that the application of the EMC cannot correct all the nonlinearity occurring under such circumstances. This has a direct consequence on the predictions, whose accuracy is significantly reduced. Also, the Creager-Paris equation validity range is questionable for such a radius (the equation was 
FIG. 9

Comparison between fracture

load predictions and

experimental fracture loads:

(a) individual tests; (b) average

values for each set of tests

(notch radius). SGFR-PA6

specimens for a fiber content of 10 wt.\%.

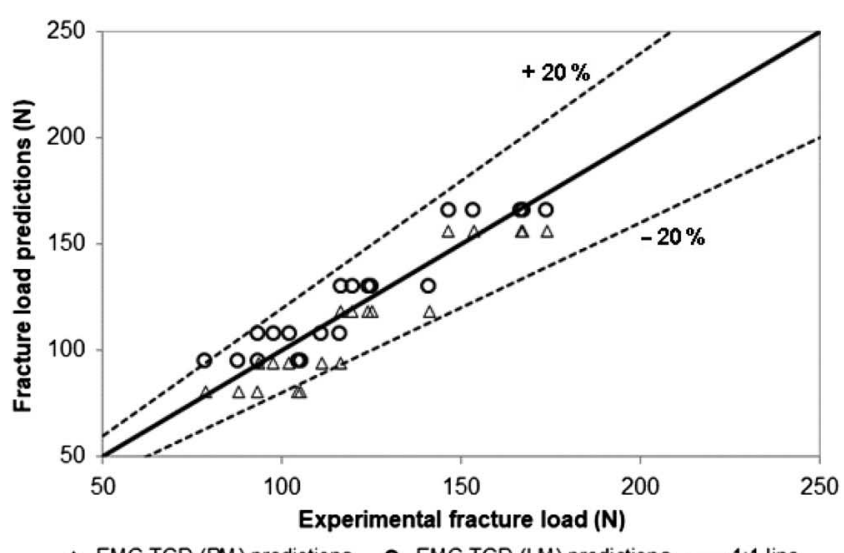

$\triangle$ EMC-TCD (PM) predictions O EMC-TCD (LM) predictions — $1: 1$ line

(a)

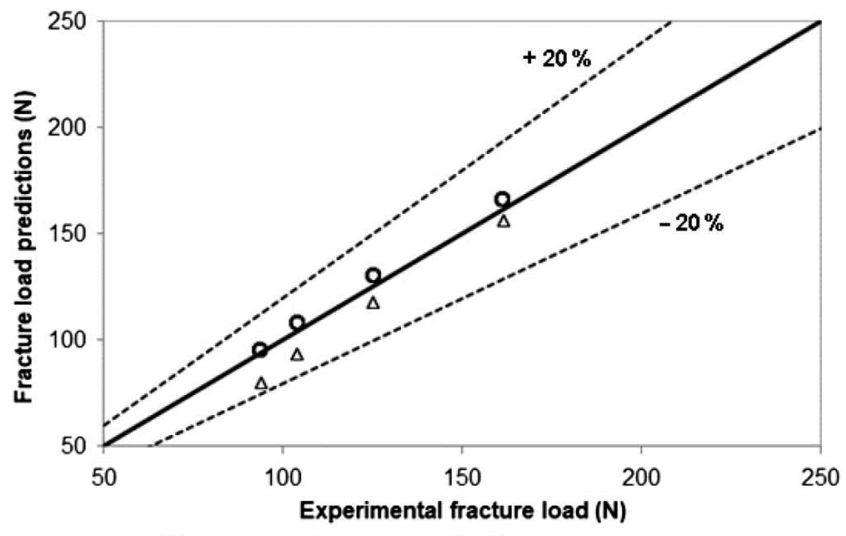

$\triangle$ EMC-TCD (PM) predictions O EMC-TCD (LM) predictions - 1:1 line

(b)

originally defined for narrow defects on which $\rho \ll a)$ [71], although it has produced accurate results for a high notch radius and low fiber contents.

When considering individual test results, there are a number of predictions outside the $\pm 20 \%$ lines (11 out of 99 predictions in the case of the LM, and 8 out of 99 predictions in the case of the PM). However, it should be noted that the experimental results themselves may have differences up to approximately $100 \%$ (e.g., results obtained in specimens with $5 \mathrm{wt}$. \% fiber content and $\rho=0.25 \mathrm{~mm}$ ). Such a degree of scatter makes it virtually impossible to derive results in which all the predictions are located within a $\pm 20 \%$ margin.

SGFR-PA6 has, for the different amounts of fiber content considered here, dominant linear-elastic behavior, but as shown in Fig. 6, the tensile curves obtained are not linear and the fracture behavior observed on notched specimens is not completely linear, especially for higher notch radii and higher amounts of fiber content. This means, in practice, that the corresponding inherent strength $\left(\sigma_{0}\right)$ does not coincide with the material ultimate tensile strength. This issue has been traditionally solved through a calibration process comprising extensive fracture testing on notched specimens or through a combination of fracture testing and FE simulations. Whichever option is selected, it results in a significantly time-consuming process that makes it difficult to extensively apply the TCD at an 
FIG. 10

Comparison between fracture load predictions and experimental fracture loads: (a) individual tests; (b) average values for each set of tests (notch radius). SGFR-PA6 specimens for a fiber content of 30 wt.\%.

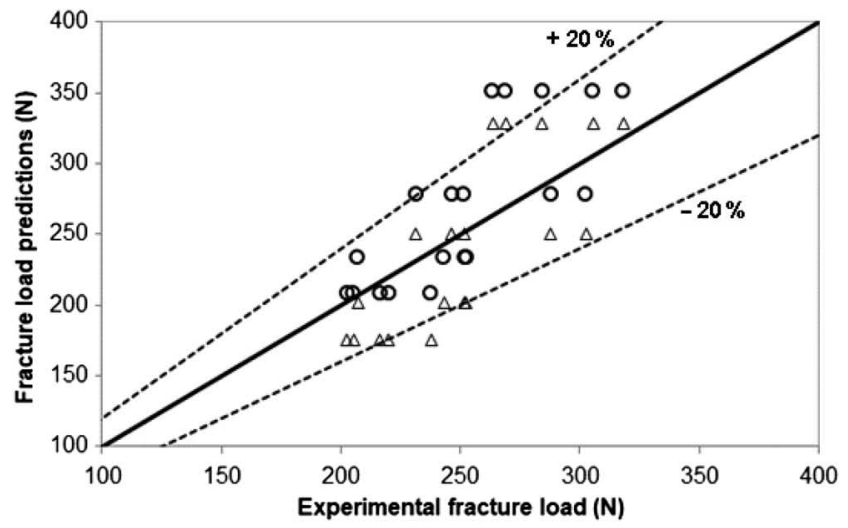

$\triangle$ EMC-TCD (PM) predictions O EMC-TCD (LM) predictions - 1:1 line

(a)

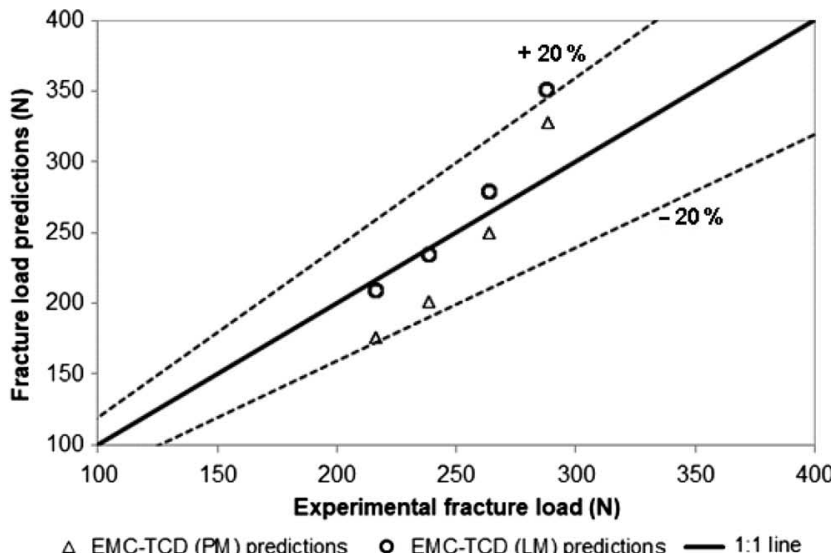

(b)

industrial level. This work essentially proposes deriving $\sigma_{0}$ from the EMC approach, assuming an equivalent fully linear-elastic material. In such circumstances, the value of $\sigma_{0}$ coincides with the value of $\sigma_{f}^{*}$ in the equivalent material, which can easily be obtained from a tensile test, and the application of the TCD is straightforward.

As can clearly be seen in Fig. 6, SGFR-PA6 has a generally elastic-plastic behavior in tension. The significant difference between $\sigma_{u}$ and $\sigma_{f}^{*}$ values suggests the same. Hence, it would be interesting to determine the failure regimes by which the tested U-notched SGFR-PA6 specimens were broken. For this purpose, two main parameters, namely the size of the plastic zone around the notch at the onset of crack initiation from the notch tip and the effective ligament, should first be computed. The second parameter is, in fact, the distance ahead of the notch tip on the notch bisector line over which the tangential stress is tensile. To calculate the size of the effective ligament, the position of the neutral axis should first be determined. In order to compute the values of these two parameters, eight elastic-plastic finite element (FE) analyses (four for the notch radius of $0.25 \mathrm{~mm}$ and four for that of $2 \mathrm{~mm}$ ) were carried out on the SENB specimen under plane-strain conditions. The true stress-strain curve of the tested SGFR-PA6 was given to the FE software, ABAQUS (Dassault Systemes, Vélizy-Villacoublay, France), point-by-point as with the 
FIG. 11

Comparison between fracture load predictions and experimental fracture loads: (a) individual tests; (b) average values for each set of tests (notch radius). SGFR-PA6 specimens for a fiber content of 50 wt.\%.

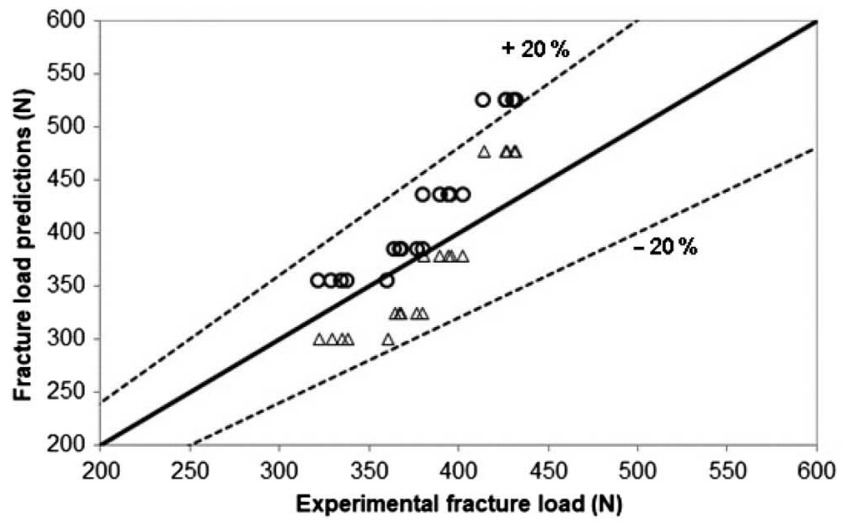

$\triangle$ EMC-TCD (PM) predictions O EMC-TCD (LM) predictions - 1:1 line (a)

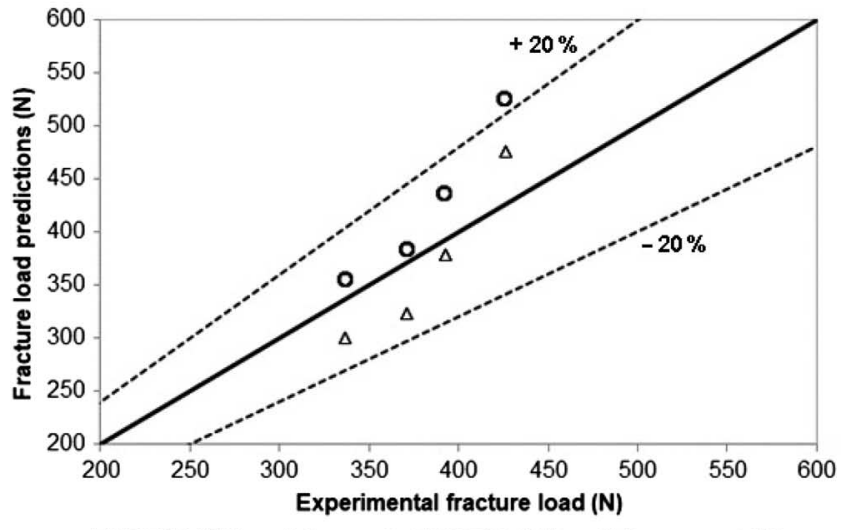

$\triangle$ EMC-TCD (PM) predictions O EMC-TCD (LM) predictions - 1:1 line

(b)

material properties. The position of the neutral axis on the notch bisector line was simply obtained as the point at which the tangential stress is zero. The distance between such a point and the notch tip is the effective ligament that was obtained to be approximately equal to $2.3 \mathrm{~mm}$ for all the notch radii. To reach the plastic zone size at failure, the VonMises stress distributions corresponding to the average of the experimentally obtained critical loads were obtained from the FE analyses and the plastic zone was recognized as the region for which the stresses are beyond the material yield strength. Fig. 12 shows the distributions of Von-Mises stress at the U-notch neighborhood for various notch radii in which the plastic zones are clearly shown. As can be seen in Fig. 12, the plastic zone size increases as the fiber content increases for both notch radii. This is trivially due to the greater plasticity of fiber-rich SGFR-PA6 materials. Also, it can be seen in this figure that for a constant fiber content, the plastic zone size increases as the notch radius increases. This is mainly due to the fact that the stress gradient for the notch radius of $2 \mathrm{~mm}$ is less than that for the notch radius of $0.25 \mathrm{~mm}$, leading to a lower concentration of the plastic zone in $2 \mathrm{~mm}$ notch radius. Dividing the plastic zone sizes shown in Fig. 12 by the effective ligament size (i.e., $2.3 \mathrm{~mm}$ ), it is obtained that for the notch radius of $0.25 \mathrm{~mm}$, about 4, 6 , 32 , and $36 \%$ of the ligament and for the notch radius of $2 \mathrm{~mm}$, about $22,44,51$, and $56 \%$ 
FIG. 12 Distributions of Von-Mises stress at the U-notch neighborhood and the plastic zone sizes determined (notch radii: $0.25 \mathrm{~mm}$ and 2 mm; fiber contents: 5 wt.\%, 10 wt.\%, 30 wt.\%, and 50 wt.\%).

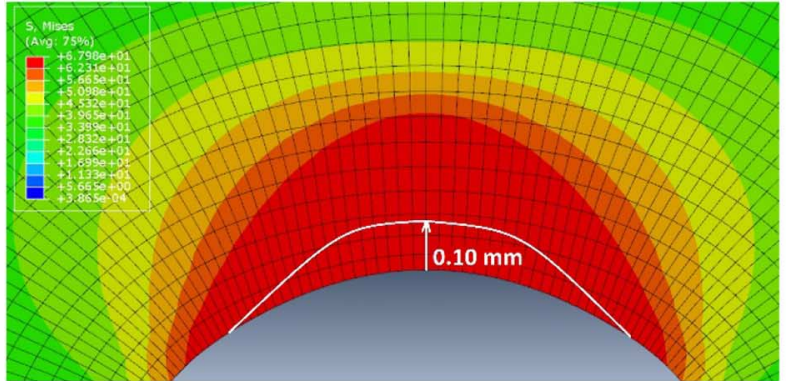

(a) 5 wt. $\% ; \rho=0.25 \mathrm{~mm}$

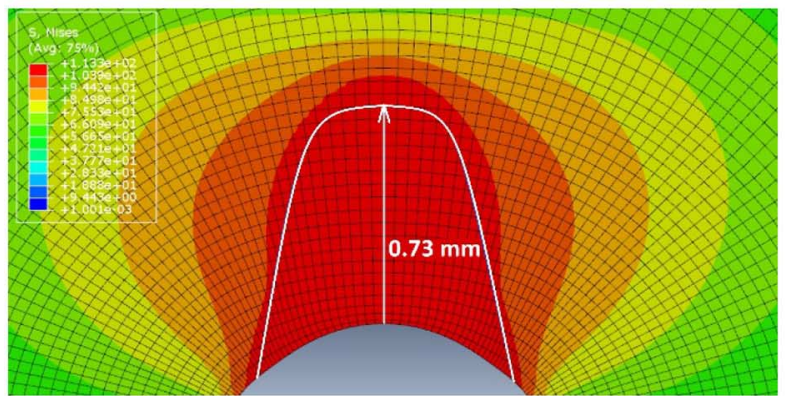

(c) 30 wt. $\% ; \rho=0.25 \mathrm{~mm}$

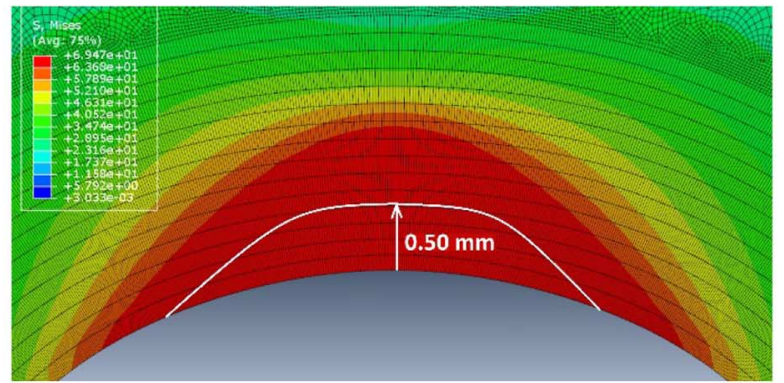

(e) 5 wt. $\% ; \rho=2 \mathrm{~mm}$

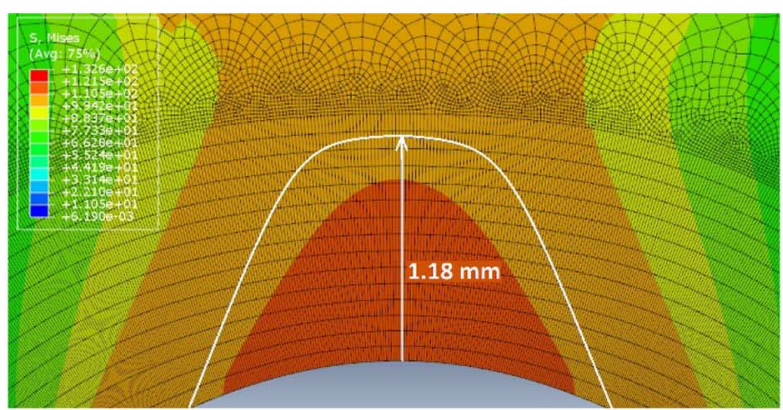

(g) 30 wt. $\% ; \rho=2 \mathrm{~mm}$

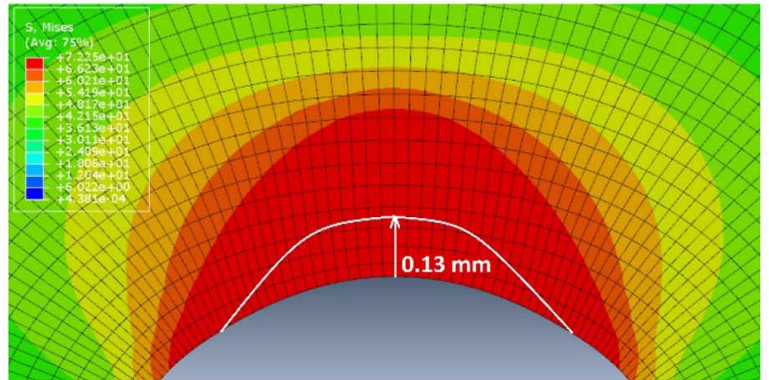

(b) 10 wt. $\% ; \rho=0.25 \mathrm{~mm}$

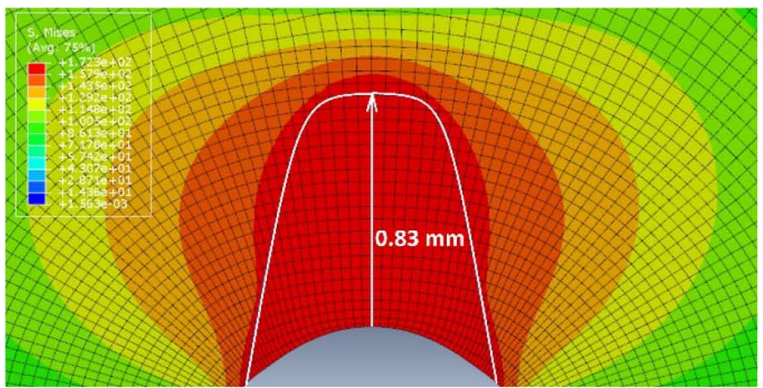

(d) 50 wt. $\% ; \rho=0.25 \mathrm{~mm}$

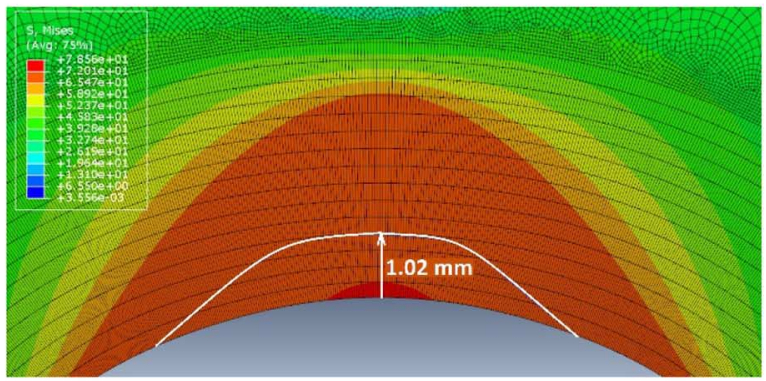

(f) 10 wt. $\% ; \rho=2 \mathrm{~mm}$

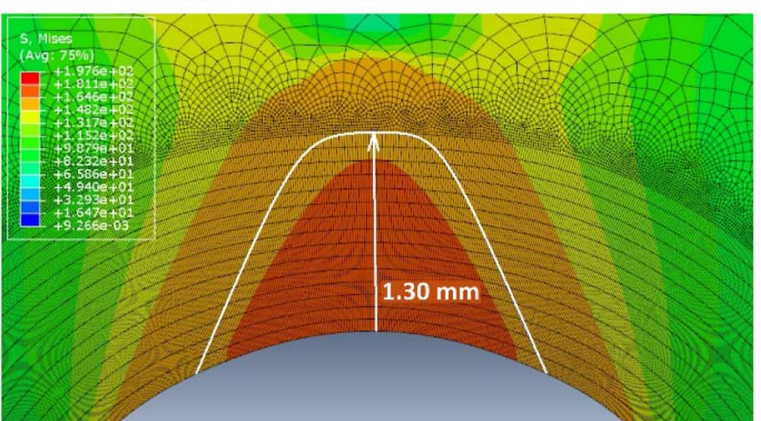

(h) 50 wt. $\% ; \rho=2 \mathrm{~mm}$

of the ligament experiences plastic deformations at failure for the four various fiber contents, respectively. Evidently, for the notch radius of $0.25 \mathrm{~mm}$, the U-notched specimens fail mainly by the small-scale yielding and moderate-scale yielding (MSY) regimes, while 
FIG. 13 Effect of fiber reinforcement on fracture micromechanisms. $\rho=0.50$ mm: (a) 5 wt.\%; (b) 10 wt.\%; (c) 30 wt.\%; (d) 50 wt.\%.

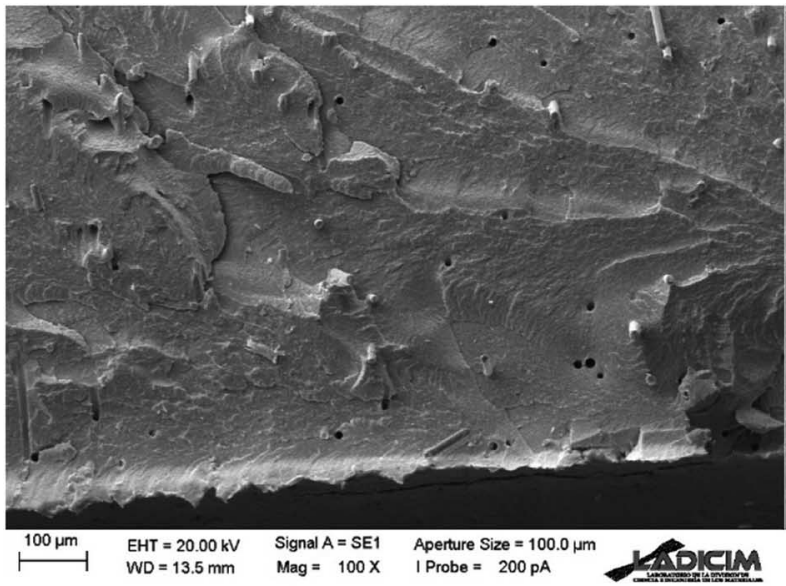

(a)

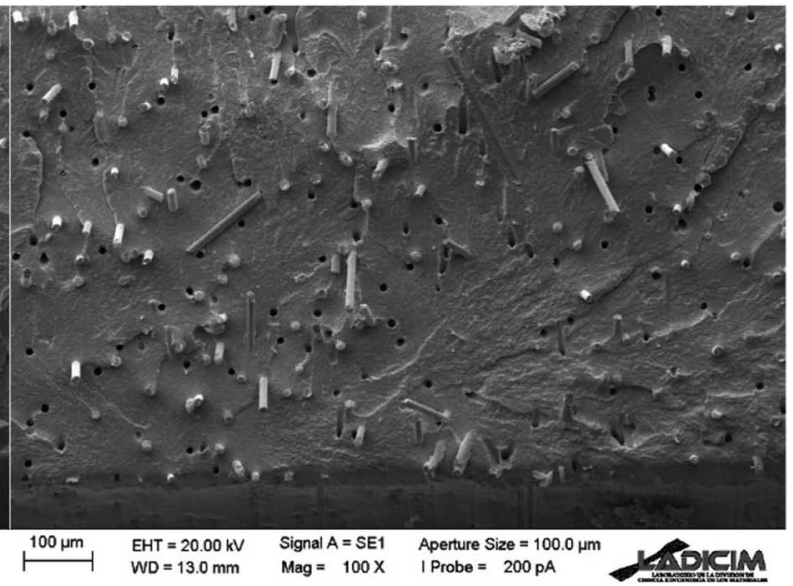

(b)

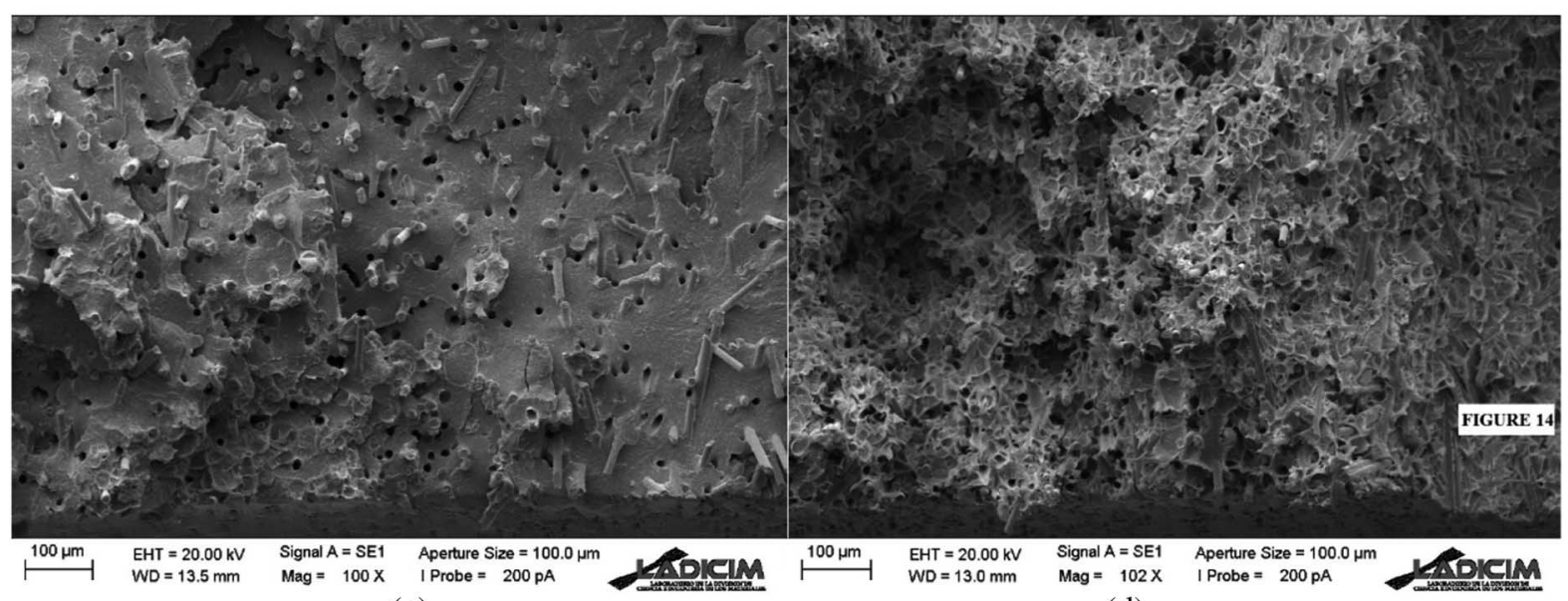

(c)

(d)

for the notch radius of $2 \mathrm{~mm}$ by MSY and large-scale yielding regimes. With all this, it can be stated that the accuracy of the EMC-TCD criterion does not significantly depend on the type of elastic-plastic failure regime, thus underlining the high effectiveness and comprehensive nature of EMC.

The evolution of the plastic zone size and the fracture loads is in agreement with the corresponding scanning electron microscopy analysis of the micromechanisms observed at the fracture surfaces, which was widely reported in Ref. [8]. As an example, Fig. 13 shows how an increase in the fiber content causes larger strains on the matrix, with a progressive development of evident nonlinear micromechanisms. Macroscopically, the roughness of the fracture surface grows when the fiber content increases, and the larger amount of nonlinear mechanisms and fiber content leads to an increase in the failure loads. Fig. 14 shows the details of the fracture mechanisms with maximum (50 wt.\%) fiber contents, including fiber pull out and shear bands, which are formed because of local stress concentrations around the fiber [72]. 
FIG. 14

Shear bands along the pulledout fiber in SGFR-PA6 (50 wt.\%; $\rho=0.50 \mathrm{~mm}$ ).

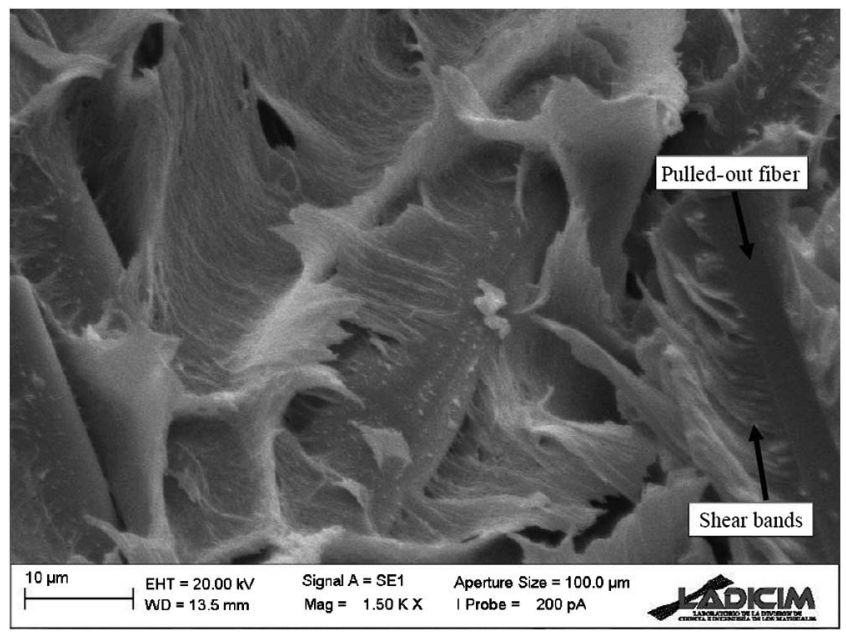

\section{Conclusions}

This article combines the TCD and the EMC to provide a simple methodology (EMC-TCD criterion) that allows the fracture loads of notched components to be determined. Here, the EMC-TCD criterion has been applied for the prediction of fracture loads in an SGFRPA6 material with different amounts of fiber content (from $5 \mathrm{wt} . \%$ up to $50 \mathrm{wt} . \%$ ) and containing $\mathrm{U}$-shaped notches (the notch radii varying from $0.25 \mathrm{~mm}$ up to $2.0 \mathrm{~mm}$ ). The analyzed materials have no fully linear-elastic material on their tensile curves, something that implies a mandatory time-consuming calibration process when the fracture behavior of this type of material is analyzed using the TCD. In order to avoid such a calibration, it is proposed to combine the TCD with the EMC, for which the nonlinear material is substituted by a perfectly linear-elastic material. This leads to the EMC-TCD criterion, which entails a fully linear-elastic formulation and does not require any calibration process beyond the equivalent material definition, which, in any case, is a straightforward process based on the material stress-strain tensile curve. The obtained results allow for the following conclusions to be stated:

- The predictions of fracture loads obtained when using the EMC-TCD criterion have been noticeably accurate for the different fiber contents analyzed, especially when using the LM as the TCD methodology. In such a case, the deviation between the predicted fracture load and the corresponding average experimental fracture load has been below $5 \%$, except for the cases of $30 \mathrm{wt} . \%$ and $50 \mathrm{wt} . \%$ fiber contents with $2.0 \mathrm{~mm}$ notch radius, for which the methodology has provided evident overestimations $(+21.7 \%$ and $+23.2 \%$, respectively).

- When using the PM, the predictions tend to be conservative, although in the case of the highest fiber contents (30 wt.\% and 50 wt.\%) combined with the highest notch radius $(2.0 \mathrm{~mm})$, the criterion has provided overestimations of the fracture loads $(+13.7 \%$ and $+11.6 \%$, respectively). In any case, the deviation of all the predictions derived from the PM are below $20 \%$.

- The elastic-plastic FE analyses of the tested U-notched specimens indicate that most of the specimens failed by significant plastic deformations around the notch, 
demonstrating that failure criteria in the context of linear elastic notch fracture mechanics may require plastic corrections or calibrations when performing fracture predictions of notched SGFR-PA6 specimens.

\section{ACKNOWLEDGMENTS}

The authors of this work would like to express their gratitude to the Spanish Ministry of Science and Innovation for the financial support of the project MAT2014-58443-P: "Análisis del Comportamiento en Fractura de Componentes Estructurales con Defectos en Condiciones de Bajo Confinamiento Tensional," on the results of which this article is based.

\section{References}

[1] Taylor, D., The Theory of Critical Distances: A New Perspective in Fracture Mechanics, Elsevier, Oxford, UK, 2007, 306p.

[2] Susmel, L. and Taylor, D., "On the Use of the Theory of Critical Distances to Predict Static Failures in Ductile Metallic Materials Containing Different Geometrical Features," Eng. Fract. Mech., Vol. 75, 2008, pp. 4410-4421, https://doi.org/10.1016/ j.engfracmech.2008.04.018

[3] Susmel, L. and Taylor, D., "The Theory of Critical Distances to Predict Static Strength of Notched Brittle Components Subjected to Mixed-Mode Loading," Eng. Fract. Mech., Vol. 75, Nos. 3-4, 2008, pp. 534-550, https://doi.org/10.1016/j.engfracmech. 2007.03.035

[4] Taylor, D., Merlo, M., Pegley, R., and Cavatorta, M. P., "The Effect of Stress Concentrations on the Fracture Strength of Polymethylmethacrylate," Mat. Sci. Eng. A., Vol. 382, Nos. 1-2, 2004, pp. 288-294, https://doi.org/10.1016/j.msea.2004.05.012

[5] Cicero, S., Madrazo, V., and Carrascal, I. A., "Analysis of Notch Effect in PMMA Using the Theory of Critical Distances," Eng. Fract. Mech., Vol. 86, 2012, pp. 56-72, https://doi.org/10.1016/j.engfracmech.2012.02.015

[6] Madrazo, V., Cicero, S., and Carrascal, I.A., "On the Point Method and the Line Method Notch Effect Predictions in Al7075-T651,” Eng. Fract. Mech., Vol. 79, 2012, pp. 363-379, https://doi.org/10.1016/j.engfracmech.2011.11.017

[7] Cicero, S., Madrazo, V., Carrascal, I. A., and Cicero, R., "Assessment of Notched Structural Components Using Failure Assessment Diagrams and the Theory of Critical Distances," Eng. Fract. Mech., Vol. 78, No. 16, 2011, pp. 2809-2825, https:// doi.org/10.1016/j.engfracmech.2011.08.009

[8] Ibáñez-Gutiérrez, F. T., Cicero, S., Carrascal, I. A., and Procopio, I., "Effect of Fibre Content and Notch Radius in the Fracture Behaviour of Short Glass Fibre Reinforced Polyamide 6: An Approach from the Theory of Critical Distances," Comp. Part B: Eng., Vol. 94, 2016, pp. 299-311, https://doi.org/10.1016/j.compositesb.2016.03.064

[9] Leguillon, D., "Strength or Toughness? A Criterion for Crack Onset at a Notch," Eur. J. Mech. A Solids, Vol. 21, No. 1, 2002, pp. 61-72, https://doi.org/10.1016/S09977538(01)01184-6

[10] Cornetti, P., Pugno, N., Carpinteri, A., and Taylor, D., "Finite Fracture Mechanics: A Coupled Stress and Energy Failure Criterion," Eng. Fract. Mech., Vol. 73, No. 14, 2006, pp. 2021-2033, https://doi.org/10.1016/j.engfracmech.2006.03.010

[11] Niu, L. S., Chehimi, C., and Pluvinage, G., "Stress Field Near a Large Blunted V Notch and Application of the Concept of Notch Stress Intensity Factor to the Fracture of Very Brittle Materials," Eng. Fract. Mech., Vol. 49, No. 3, 1994, pp. 325-335, https:// doi.org/10.1016/0013-7944(94)90262-3

[12] Pluvinage, G., "Fatigue and Fracture Emanating from Notch, the Use of the Notch Stress Intensity Factor," Nucl. Eng. Des., Vol. 185, Nos. 2-3, 1998, pp. 173-184.

[13] Dugdale, D. S., "Yielding of Steel Sheets Containing Slits," J. Mech. Phys. Solids., Vol. 8, No. 2, 1960, pp. 100-108, https://doi.org/10.1016/0022-5096(60)90013-2 
[14] Barenblatt, G. I., "The Formation of Equilibrium Cracks during Brittle Fracture. General Ideas and Hypothesis. Axially Symmetric Cracks," J. Appl. Math. Mech., Vol. 23, No. 3, 1959, pp. 622-636, https://doi.org/10.1016/0021-8928(59)90157-1

[15] Hilleborg, A., Modeer, M., and Petersson, P. E., "Analysis of Crack Formation and Crack Growth in Concrete by Means of Fracture Mechanics and Finite Elements," Cem. Concr. Res. Vol. 6, No. 6, 1976, pp. 777-782.

[16] Gómez, F. J., Elices, M., and Valiente, A., "Cracking in PMMA Containing U-Shaped Notches," Fat. Frac. Eng. Mat. Struct., Vol. 23, No. 9, 2000, pp. 795-803, https://doi. org/10.1046/j.1460-2695.2000.00264.x

[17] Lawn, B., Fracture of Brittle Solids, Cambridge University Press, Cambridge, UK, 1993, 378p.

[18] Weibull, W., "The Phenomenon of Rupture in Solids," Proc. R. Swed. Inst. Eng. Res., Vol. 153, 1939, pp. 1-55.

[19] Beremin, F. M., Pineau, A., Mudry, F., Devaux, J. C., D'Escatha, Y., and Ledermann, P., "A Local Criterion for Cleavage Fracture of a Nuclear Pressure Vessel Steel," Metall. Trans. A., Vol. 14, No. 11, 1983, pp. 2277-2287, https://doi.org/10.1007/BF02663302

[20] Ritchie, R. O., Knott, J. F., and Rice, J. R., "On the Relationship between Critical Tensile Stress and Fracture Toughness in Mild Steel," J. Mech. Phys. Solids., Vol. 21, No. 6, 1973, pp. 395-410, https://doi.org/10.1016/0022-5096(73)90008-2

[21] Ayatollahi, M. R., Razavi, S. M. J., Rashidi Moghaddam, M., and Berto, F., "Mode I Fracture Analysis of Polymethylmetacrylate Using Modified Energy-Based Models," Phys. Mesomech., Vol. 18, No. 4, 2015, pp. 326-336, https://doi.org/10.1134/ S1029959915040050

[22] Ayatollahi, M. R., Rashidi Moghaddam, M., Razavi, S. M. J., and Berto, F, “Geometry Effects on Fracture Trajectory of PMMA Samples under Pure Mode-I Loading," Eng. Fract. Mech., Vol. 163, 2016, pp. 449-461, https://doi.org/10.1016/j.engfracmech. 2016.05.014

[23] Rashidi Moghaddam, M., Ayatollahi, M. R., Razavi, S. M. J., and Berto, F., "Mode II Brittle Fracture Assessment Using an Energy Based Criterion," Phys. Mesomech., Vol. 20, No. 2, 2017, pp. 142-148, https://doi.org/10.1134/S1029959917020047

[24] Sih, G. C., "Strain-Energy-Density Factor Applied to Mixed Mode Crack Problems," Int. J. Fract., Vol. 10, No. 3, 1974, pp. 305-321, https://doi.org/10.1007/BF00035493

[25] Kipp, M. E. and Sih, G. C., "The Strain Energy Density Failure Criterion Applied to Notched Elastic Solids," Int. J. Solids Struct., Vol. 11, No. 2, 1975, pp. 153-173, https:// doi.org/10.1016/0020-7683(75)90050-5

[26] Gillemot, L. F., "Criterion of Crack Initiation and Spreading," Eng. Fract. Mech., Vol. 8, 1976, pp. 239-253, https://doi.org/10.1016/0013-7944(76)90089-8

[27] Molski, K. and Glinka, G., "A Method of Elastic-Plastic Stress and Strain Calculation at a Notch Root," Mat. Sci. Eng., Vol. 50, No. 1, 1981, pp. 93-100, https://doi.org/10. 1016/0025-5416(81)90089-6

[28] Berto, F. and Lazzarin, P., "Recent Developments in Brittle and Quasi-Brittle Failure Assessment of Engineering Materials by Means of Local Approaches," Mat. Sci. Eng. R., Vol. 75, 2014, pp. 1-48, https://doi.org/10.1016/j.mser.2013.11.001

[29] Lazzarin, P. and Berto, F., "Some Expressions for the Strain Energy in a Finite Volume Surrounding the Root of Blunt V-Notches," Int. J. Fract., Vol. 135, Nos. 1-4, 2005, pp. 161-185.

[30] Berto, F., "A Criterion Based on the Local Strain Energy Density for the Fracture Assessment of Cracked V-Notched Components Made of Incompressible Hyperelastic Materials," Theor. Appl. Fract. Mech., Vol. 76, 2015, pp. 17-26, https://doi.org/10.1016/j.tafmec.2014.12.008

[31] Berto, F. and Lazzarin, P., "Fictitious Notch Rounding Approach of Pointed V-Notch Under In-Plane Shear," Theor. Appl. Fract. Mech., Vol. 53, No. 2, 2010, pp. 127-135, https://doi.org/10.1016/j.tafmec.2010.03.003

[32] Gallo, P., Berto, F., and Lazzarin, P., "High Temperature Fatigue Test of Notched Specimens Made of Titanium Grade 2," Theor. Appl. Fract. Mech., Vol. 76, 2015, pp. 27-34, https://doi.org/10.1016/j.tafmec.2014.12.007 
[33] Berto, F. and Lazzarin, P., "A Review of the Volume-Based Strain Energy Density Approach Applied to V-Notches and Welded Structures," Theor. Appl. Fract. Mech., Vol. 52, No. 3, 2009, pp. 183-194, https://doi.org/10.1016/j.tafmec.2009.10.001

[34] Campagnolo, A., Berto, F., and Leguillon, D., "Fracture Assessment of Sharp V-Notched Components under Mode II Loading: A Comparison among Some Recent Criteria," Theor. Appl. Fract. Mech., Vol. 85B, 2016, pp. 217-226, https://doi.org/10.1016/ j.tafmec.2016.02.001

[35] Berto, F., Cendón, D. A., and Elices, M., "Fracture Behavior under Torsion of Notched Round Bars Made of Gray Cast Iron," Theor. Appl. Fract. Mech., Vol. 84, 2016, pp. 157-165, https://doi.org/10.1016/j.tafmec.2016.03.001

[36] Derpeński, L., Seweryn, A., and Berto, F., "Brittle Fracture of Axisymmetric Specimens with Notches Made of Graphite EG0022A," Theor. Appl. Fract. Mech., Vol. 89, 2017, pp. 45-51, https://doi.org/10.1016/j.tafmec.2017.01.007

[37] Lazzarin, P., Campagnolo, A., and Berto, F., "A Comparison among Some Recent Energy- and Stress-Based Criteria for the Fracture Assessment of Sharp V-Notched Components under Mode I Loading," Theor. Appl. Fract. Mech., Vol. 71, 2014, pp. 21-30, https://doi.org/10.1016/j.tafmec.2014.03.001

[38] Gallo, P., Berto, F., and Glinka, G., "Analysis of Creep Stresses and Strains around Sharp and Blunt V-Notches," Theor. Appl. Fract. Mech., Vol. 85B, 2016, pp. 435-446, https://doi.org/10.1016/j.tafmec.2016.06.003

[39] Kocak, M., Webster, S., Janosch, J. J., Ainsworth, R. A., and Koers, R., FITNET Fitness-for-Service (FFS), GKSS Research Center, Hamburg, Germany, 2008, pp. 6-1-6-54.

[40] Berto, F., Lazzarin, P., Kotousov, A., and Pook, L.P., "Induced Out-of-Plane Mode at the Tip of Blunt Lateral Notches and Holes under In-Plane Shear Loading," Fat. Fract. Eng. Mater. Struct., Vol. 35, No. 6, 2012, pp. 538-555, https://doi.org/10.1111/ j.1460-2695.2011.01647.x

[41] He, Z., Kotousov, A., and Berto, F., "Effect of Vertex Singularities on Stress Intensities Near Plate Free Surfaces," Fat. Fract. Eng. Mater. Struct., Vol. 38, No. 7, 2015, pp. 860-869, https://doi.org/10.1111/ffe.12294

[42] Cicero, S., Madrazo, V., and García, T., "The Notch Master Curve: A Proposal of Master Curve for Ferritic-Pearlitic Steels in Notched Conditions," Eng. Fail. Anal., Vol. 42, 2014, pp. 178-196, https://doi.org/10.1016/j.engfailanal.2014.04.007

[43] Cicero, S., García, T., and Madrazo, V., "Application and Validation of the Notch Master Curve in Medium and High Strength Structural Steels," J. Mech. Sci. Technol., Vol. 29, No. 10, 2015, pp. 4129-4142, https://doi.org/10.1007/s12206-015-0907-2

[44] Madrazo, V., Cicero, S., and García, T., "Assessment of Notched Structural Steel Components Using Failure Assessment Diagrams and the Theory of Critical Distances," Eng. Fail. Anal., Vol. 36, 2014, pp. 104-120, https://doi.org/10.1016/ j.engfailanal.2013.09.012

[45] Ibáñez-Gutiérrez, F. T. and Cicero, S., "Fracture Assessment of Notched Short Glass Fibre Reinforced Polyamide 6: An Approach from Failure Assessment Diagrams and the Theory of Critical Distances," Comp. Part B Eng. Vol. 111, 2017, pp. 124-133, https://doi.org/10.1016/j.compositesb.2016.11.053

[46] Cicero, S., Madrazo, V., and García, T., "On the Assessment of U-Shaped Notches Using Failure Assessment Diagrams and the Line Method: Experimental Overview and Validation," Theor. Appl. Fract. Mech., Vol. 80, 2015, pp. 235-241, https://doi. org/10.1016/j.tafmec.2015.07.002

[47] Torabi, A. R., "Estimation of Tensile Load-Bearing Capacity of Ductile Metallic Materials Weakened by a V-Notch: The Equivalent Material Concept," Mat. Sci. Eng. A., Vol. 536, 2012, pp. 249-255, https://doi.org/10.1016/j.msea.2012.01.007

[48] Torabi, A. R., "On the Use of the Equivalent Material Concept to Predict Tensile LoadBearing Capacity of Ductile Steel Bolts Containing V-Shaped Threads," Eng. Fract. Mech., Vol. 97, 2013, pp. 136-147, https://doi.org/10.1016/j.engfracmech.2012.10.021 
[49] Torabi, A. R. and Alaei, M., "Mixed-Mode Ductile Failure Analysis of V-Notched Al 7075-T6 Thin Sheets," Eng. Fract. Mech., Vol. 150, 2015, pp. 70-95, https://doi.org/ 10.1016/j.engfracmech.2015.10.037

[50] Torabi, A. R, Habibi, R., and Mohammad Hosseini, B., "On the Ability of the Equivalent Material Concept in Predicting Ductile Failure of U-Notches under Moderate- and Large-Scale Yielding Conditions," Phys. Mesomech., Vol. 18, No. 4, 2015, pp. 337-347, https://doi.org/10.1134/S1029959915040062

[51] Torabi, A. R. and Habibi, R., "Investigation of Ductile Rupture in U-Notched Al 6061-T6 Plates under Mixed Mode Loading," Fat. Fract. Eng. Mater. Struct., Vol. 39, 2016, pp. 551-565, https://doi.org/10.1111/ffe.12376

[52] Torabi, A. R. and Keshavarzian, M., "Evaluation of the Load-Carrying Capacity of Notched Ductile Plates under Mixed Mode Loading," Theor. Appl. Fract. Mech., Vol. 85, 2016, pp. 375-386, https://doi.org/10.1016/j.tafmec.2016.04.009

[53] Torabi, A. R. and Keshavarzian, M., "Tensile Crack Initiation from a Blunt V-Notch Border in Ductile Plates in the Presence of Large Plasticity at the Notch Vicinity," Int. J. Terrasp. Sci. Eng., Vol. 8, 2016, pp. 93-101.

[54] Torabi, A. R. and Alaei, M., "Application of the Equivalent Material Concept to Ductile Failure Prediction of Blunt V-Notches Encountering Moderate-Scale Yielding," Int. J. Damage Mech., Vol. 25, No. 6, 2016, pp. 853-877, https://doi.org/ $10.1177 / 1056789515625451$

[55] Torabi, A. R. and Mohammad Hosseini, B., "Large Plasticity Induced Crack Initiation from U-Notches in Thin Aluminum Sheets under Mixed Mode Loading," Eng. Solid Mech., Vol. 5, No. 1, 2017, pp. 39-60, https://doi.org/10.5267/j.esm.2016.10.001

[56] Torabi, A. R., Berto, F., and Razavi, S. M. J., "Ductile Failure Prediction of Thin Notched Aluminum Plates Subjected to Combined Tension-Shear Loading," Theor. Appl. Fract. Mech., Vol. 97, 2018, pp. 280-288, https://doi.org/10.1016/j.tafmec.2017.05.003

[57] Torabi, A. R., Berto, F., Campagnolo, A., and Akbardoost, J., "Averaged Strain Energy Density Criterion to Predict Ductile Failure of U-Notched Al 6061-T6 Plates under Mixed Mode Loading," Theor. Appl. Fract. Mech., Vol. 91, 2017, pp. 86-93, https:// doi.org/10.1016/j.tafmec.2017.04.010

[58] Torabi, A. R., Campagnolo, A., and Berto, F., "Mixed Mode I/II Crack Initiation from U-Notches in Al 7075-T6 Thin Plates by Large-Scale Yielding Regime," Theor. Appl. Fract. Mech., Vol. 86, 2016, pp. 284-291, https://doi.org/10.1016/j.tafmec.2016.08.002

[59] Torabi, A. R., Campagnolo, A., and Berto, F., "A Successful Combination of the Equivalent Material Concept and the Averaged Strain Energy Density Criterion for Predicting Crack Initiation from Blunt V-Notches in Ductile Aluminium Plates under Mixed Mode Loading," Phys. Mesomech., Vol. 19, No. 4, 2016, pp. 382-391, https://doi.org/10.1134/S1029959916040056

[60] Torabi, A. R., Berto, F., and Campagnolo, A., "Elastic-Plastic Fracture Analysis of Notched Al 7075-T6 Plates by Means of the Local Energy Combined with the Equivalent Material Concept," Phys. Mesomech., Vol. 19, No. 2, 2016, pp. 204-214, https://doi.org/10.1134/S1029959916020144

[61] Torabi, A. R., Berto, F., and Razavi, S. M. J., "Tensile Failure Prediction of U-Notched Plates under Moderate-Scale and Large-Scale Yielding," Theor. Appl. Fract. Mech., Vol. 97, 2018, pp. 434-439, https://doi.org/10.1016/j.tafmec.2017.07.009

[62] Mallick, P. K., Fiber Reinforced Composites: Materials, Manufacturing, and Design, CRC Press, Boca Raton, FL, 2007, 638p.

[63] Brydson, J. A., Plastics Materials, 5th ed., Butterworth-Heinemann, London, UK, 1989, 864p.

[64] Crawford, R., Plastics Engineering, Pergamon Press, Oxford, UK, 1983, 352p.

[65] Broge, J. L., "Ford's Prototype Electric Ka," Automot. Eng., Vol. 108, 2000, pp. 28-32.

[66] Esveld, C., Modern Railway Track, MRT Productions, Duisburg, Germany, 1989, 87p.

[67] Neuber, H., Theory of Notch Stresses: Principles for Exact Calculation of Strength with Reference to Structural Form and Material, Springer, Verlag, Berlin, 1958, 293p.

[68] Peterson, R. E., "Notch Sensitivity," Metal Fatigue, McGraw Hill, New York, NY, USA, 1959, pp. 293-306. 
[69] ASTM D638-10, Standard Test Method for Tensile Properties of Plastics, ASTM International, West Conshohocken, PA, 2010, www.astm.org

[70] ASTM D5045-99, Standard Test Methods for Plane-Strain Fracture Toughness and Strain Energy Release Rate of Plastic Material, ASTM International, West Conshohocken, PA, 1999, www.astm.org

[71] Creager, M. and Paris, P. C., "Elastic Field Equations for Blunt Cracks with Reference to Stress Corrosion Cracking," Int. J. Fract., Vol. 3, No. 4, 1967, pp. 247-252, https:// doi.org/10.1007/BF00182890

[72] Razavi, S. M. J., Ayatollahi, M. R., Esmaeili, E., and da Silva, L. F. M., "Mixed-Mode Fracture Response of Metallic Fiber-Reinforced Epoxy Adhesive," Eur. J. Mech. A Solids, Vol. 65, 2017, pp. 349-359, https://doi.org/10.1016/j.euromechsol.2017.06.001 